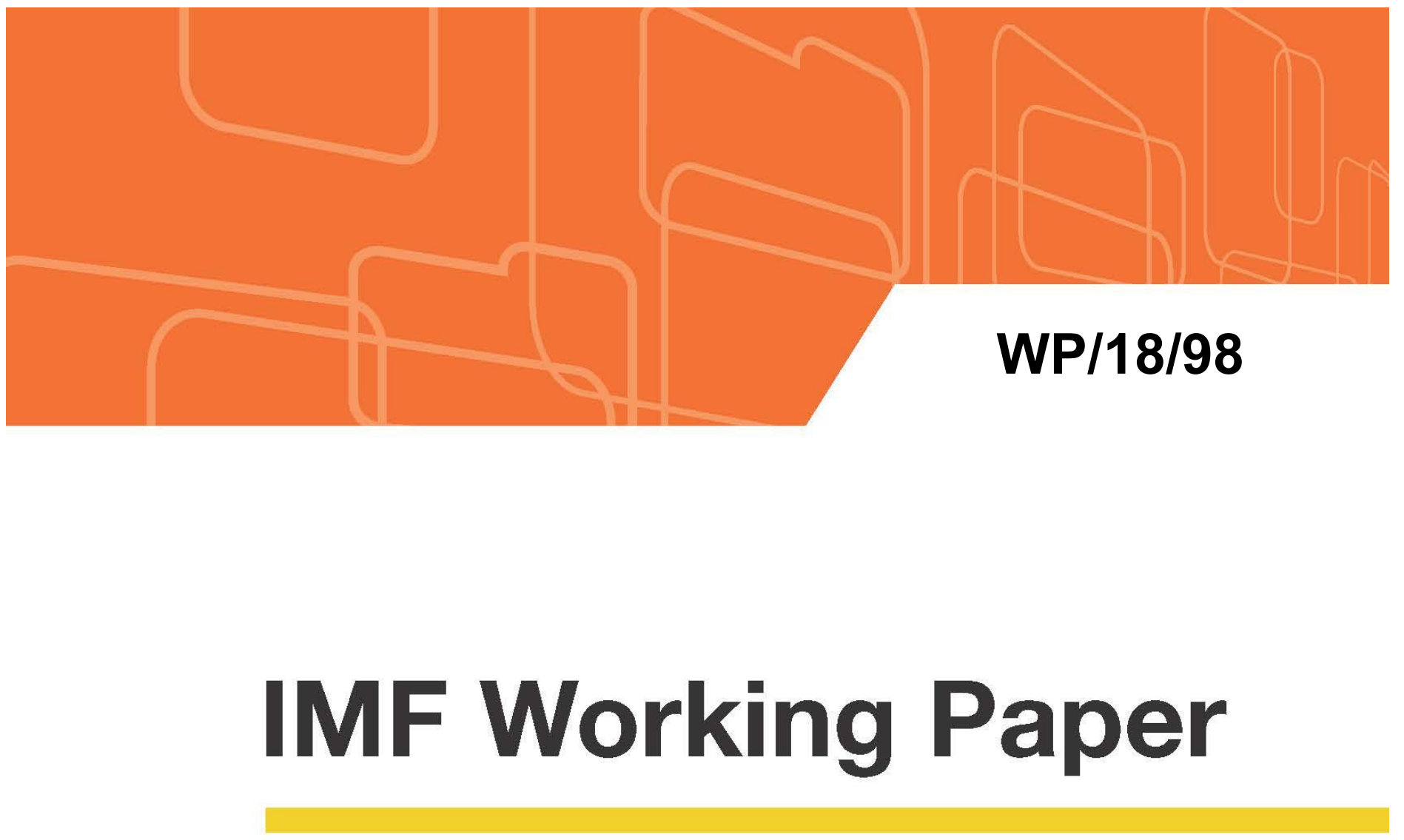

\title{
Oil Prices and GCC Stock Markets: New Evidence from Smooth Transition Models
}

By Nidhaleddine Ben Cheikh, Sami Ben Naceur, Oussama Kanaan, and Christophe Rault

IMF Working Papers describe research in progress by the author(s) and are published to elicit comments and to encourage debate. The views expressed in IMF Working Papers are those of the author(s) and do not necessarily represent the views of the IMF, its Executive Board, or IMF management. 


\title{
IMF Working Paper
}

Institute for Capacity Development

\section{Oil Prices and GCC Stock Markets: New Evidence from Smooth Transition Models}

\author{
Prepared by Nidhaleddine Ben Cheikh, Sami Ben Naceur, Oussama Kanaan, and \\ Christophe Rault ${ }^{1}$
}

Authorized for distribution by Ralph Chami

May 2018

IMF Working Papers describe research in progress by the author(s) and are published to elicit comments and to encourage debate. The views expressed in IMF Working Papers are those of the author(s) and do not necessarily represent the views of the IMF, its Executive Board, or IMF management.

\begin{abstract}
Our paper examines the effect of oil price changes on Gulf Cooperation Council (GCC) stock markets using nonlinear smooth transition regression (STR) models. Contrary to conventional wisdom, our empirical results reveal that GCC stock markets do not have similar sensitivities to oil price changes. We document the presence of stock market returns' asymmetric reactions in some GCC countries, but not for others. In Kuwait's case, negative oil price changes exert larger impacts on stock returns than positive oil price changes. When considering the asymmetry with respect to the magnitude of oil price variation, we find that Oman's and Qatar's stock markets are more sensitive to large oil price changes than to small ones. Our results highlight the importance of economic stabilization and reform policies that can potentially reduce the sensitivity of stock returns to oil price changes, especially with regard to the existence of asymmetric behavior.
\end{abstract}

JEL Classification Numbers: G12, F3, Q43

Keywords: GCC stock markets, oil prices, smooth transition regression models

Authors’ E-Mail Addresses: nidhaleddine.bencheikh@essca.fr, sbennaceur@imf.org, okanaan@imf.org, chrault@ hotmail.com

\footnotetext{
${ }^{1}$ Nidhaleddine Ben Cheikh is an Associate Professor of Economics at the ESSCA School of Management, France; Sami Ben Naceur is Deputy Division Chief in the Institute for Capacity Development at the International Monetary Fund; Oussama Kanaan is the Director of the IMF Middle East Center of Economics and Finance in Kuwait (CEF); and Christophe Rault is a Full Professor of Economics at the University of Orléans (CNRS, LEO FRE 2014), France. The authors would like to thank Basil Awad from the CEF for preparing the database and writing Section 2 of the paper; Noor Tarawneh, Margarita Guissela Aguilar Calvay, Botir Baltabaev, and Ling Zhu for their comments on an earlier version of our paper; Lisette Atiyeh for editorial assistance; and Aliya Levinstein, Natalie Tate, Jennifer Azar, and Theresa Nakamura for administrative assistance. All errors and omissions are our own.
} 


\section{CONTENTS}

I. Introduction

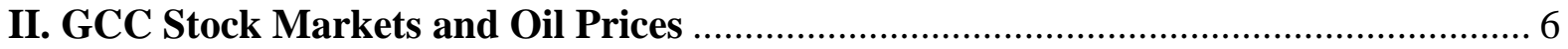

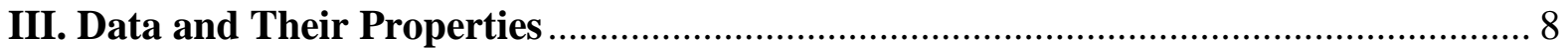

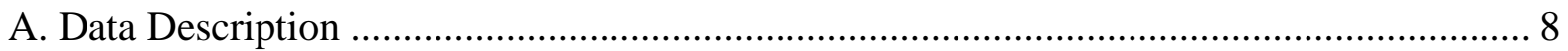

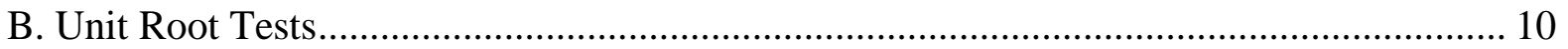

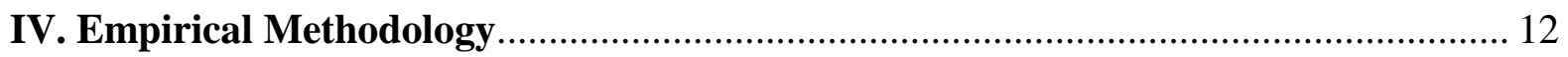

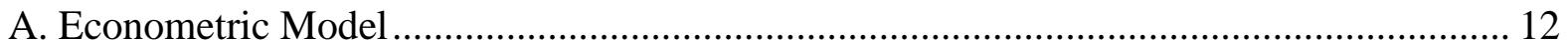

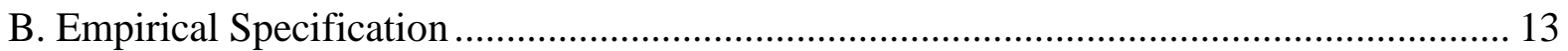

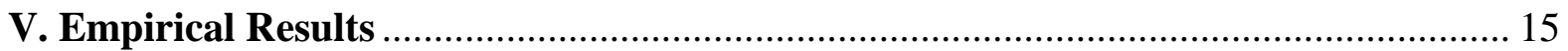

A. Asymmetry Between Positive and Negative Oil Price Changes........................................ 17

B. Asymmetry Between Small and Large Oil Price Changes ................................................ 20

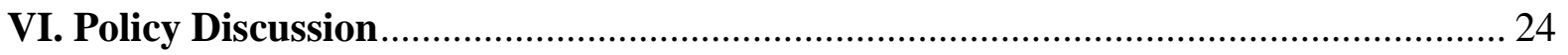

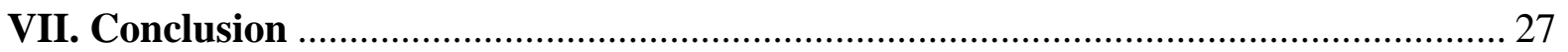

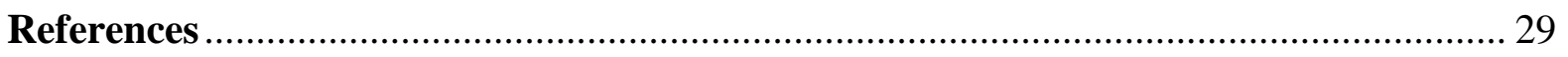

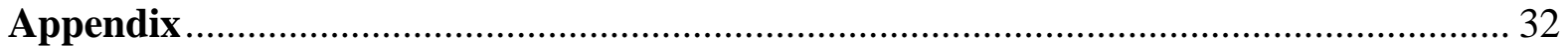

Figures

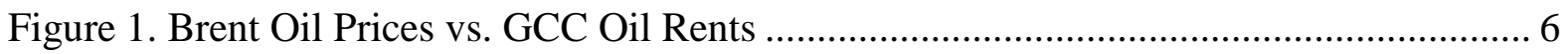

Figure 2. GCC Stock Market: Listed Companies and Market Capitalization ............................ 7

Figure 3. GCC Stock Market Indices and Brent Oil Prices over the Last Decade ................... 9

Figure 4. Logistic Functions and Long-Run Effects of Oil Prices ....................................... 19

Figure 5. Time-Varying Long-Run Impacts of Oil Prices on Stock Returns Using LSTR

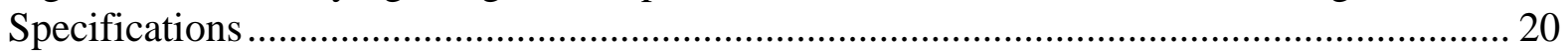

Figure 6. Exponential Functions and Long-Run Effects of Oil Prices .................................. 22

\section{Tables}

Table 1. GCC Markets in 2015 .......................................................................................... 7

Table 2. Descriptive Statistics for Stock and Crude Market Returns ...................................... 9

Table 3. Cross-Correlation Coefficients Among Stock Markets and Oil Returns ................... 10

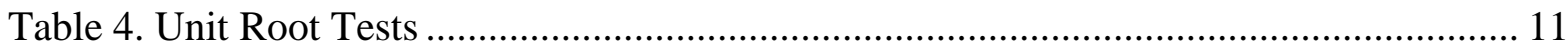

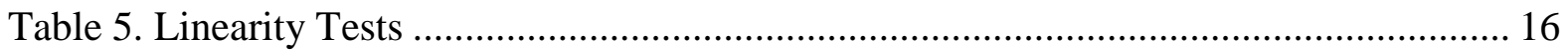

Table 6. Estimated Impacts of Oil Returns on GCC Stock Markets Using LSTR

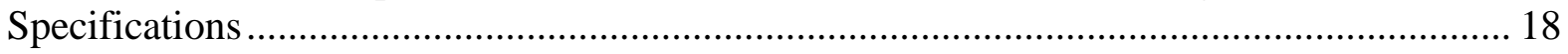

Table 7. Estimated Impacts of Oil Returns on GCC Stock Markets Using ESTR

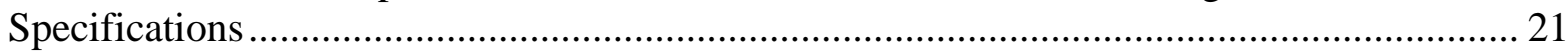

Table A1. Full Estimation Results from LSTR Specifications .............................................. 32

Table A2. Full Estimation Results from ESTR Specifications ............................................... 34 


\section{INTRODUCTION}

Over the past decade, many papers have been investigating the relationships between oil prices and macroeconomic variables. They provide evidence proving that oil price fluctuations exert large impacts on economic activity in developed and emerging economies (see Gronwald, 2008; Cologni and Manera, 2008; or Kilian, 2008). However, less emphasis has been placed on studying the link between oil price movement and the stock market. Furthermore, most of the existing papers have studied stock markets in developed economies, while developing and emerging market countries, including Gulf Cooperation Council (GCC) countries, have remained relatively unexplored. Additionally, most of these studies have relied on linear econometric frameworks for modelling the interactions between oil price shocks and stock markets, and it is now well established that overlooking potential nonlinearity can lead to misleading results (see Balcilar et al., 2015).

There are at least four reasons for studying the GCC region. First, these countries are large suppliers of oil for the global economy, so their stock markets may be influenced by oil price movements. Second, GCC markets are, to some extent, segmented from international markets, but very sensitive to regional political events. Third, GCC markets are unique, very promising places for international portfolio diversification. Fourth, only a few studies have investigated the nonlinear relationship between oil prices and stock markets in the GCC region.

During the last ten years, the crude oil market has experienced huge swings, such as the spectacular increase in oil price in 2007 and early 2008, and the subsequent dramatic decline at the end of 2008. In conjunction with the dramatic change in the financial environment since the eruption of the US subprime crisis, the presence of structural breaks and regime shifts has revived the belief in an asymmetric, nonlinear relationship between oil prices and stock markets. ${ }^{2}$ A more thorough understanding of this relationship would be especially valuable for policymakers in countries that are heavily reliant on oil for their export earnings and fiscal revenues, such as GCC countries, which are seeking to predict and temper the impact of oil price change on the stock market more effectively. It could also serve to identify the macroeconomic stabilization and reform measures that are key to reducing stock market sensitivity to oil price changes.

As is well known, the sign of the relationship between oil prices and stock indices depends on whether a country is a net oil-importing or oil-exporting economy. ${ }^{3}$ The literature finds GCC stock markets and oil prices to be significantly and positively correlated. In a recent paper, Dutta et al. (2017) report a positive, significant relationship between oil prices and realized stock market uncertainties — even after controlling for global stock market uncertainty — in Saudi Arabia, Kuwait, the United Arab Emirates (UAE), and Qatar. Using a

\footnotetext{
${ }^{2}$ As argued by Koop and Potter (2000), much of the evidence for nonlinearity in economic time series might, in fact, be due to structural changes.

${ }^{3}$ For instance, Park and Ratti (2008) revealed that oil price spikes have negative impacts on stock returns in the US and 12 European countries, whereas stock markets in Norway (an oil-exporting country) respond positively to oil price increases.
} 
VAR-GARCH model, Al-Maadid et al. (2016) also find that GCC stock markets and oil prices are highly and positively correlated. Others have studied volatility spillovers between oil prices and GCC stock markets. Arouri et al. (2011) find return and volatility spillovers between oil prices and GCC stock markets. Almohaimeed and Harrathi (2013) report a significant volatility spillover between the Saudi stock market and oil prices. Jouini and Harrathi (2014) observe a volatility spillover running from oil market volatility to GCC stock price volatility, and vice versa.

More recently, there has been increasing interest in studying the potential asymmetric effects of oil price shocks on stock returns, although the number of studies is still relatively sparse. The existing empirical literature has focused on the asymmetry arising from the direction of oil price change, in the sense that stock prices respond asymmetrically to oil price decreases and increases (see Park and Ratti, 2008; Sim and Zhou, 2015; Reboredo and Ugolini, 2016; and Mohanty et al., 2011). ${ }^{4}$ However, in spite of its policy relevance, little is said about whether oil price shocks are asymmetric in magnitude, namely, if the effects of large oil price changes on stock prices prove to be different from the effects of smaller shocks. Furthermore, ad hoc methods have often been implemented to measure the asymmetric reactions of stock market returns to oil price changes. For instance, in a sample of GCC countries, Mohanty et al. (2011) introduce a dummy variable to capture the asymmetry with respect to oil price decreases and increases. While declines in oil prices negatively impact all GCC stock markets, Mohanty et al. (2011) reveal that oil price increases have mixed effects on stock returns. Since linear and ad hoc approaches would potentially lead to counterintuitive, mixed results, we propose the use of a class-regime-switching model, where the nonlinear dynamic is generated endogenously from the data.

Our paper aims to shed further light on the asymmetries in the sensitivity levels of GCC stock markets to oil prices. We propose to implement a relevant econometric method that enables us to explore the two possible sources of asymmetry in stock price reactions, namely, the direction and magnitude of oil price change. We use the class of nonlinear smooth transition regression (STR) models, where different regimes can be identified with respect to estimated thresholds. To capture the asymmetry arising from the direction of oil price shock, we use a logistic specification of the STR model (LSTR), which is appropriate for separating oil price into positive and negative changes. However, an exponential form of the STR model (ESTR) is more suitable for distinguishing between large and small oil price changes when capturing asymmetric behavior with respect to the size of oil price's movement. Our study is conducted for a sample of six GCC countries (Bahrain, Kuwait, Oman, Qatar, Saudi Arabia, and the UAE), using monthly data over January 2004-December 2015. To the best of our knowledge, no other study has applied a nonlinear STR approach in this context.

Despite the apparent common economic and political characteristics shared by GCC countries, our results reveal heterogeneous reactions in their respective equity markets with respect to oil price variations. We find that Kuwait's stock market responds asymmetrically to oil price decreases and increases, with negative deviations exerting larger impacts than positive ones.

\footnotetext{
${ }^{4}$ It is worth highlighting that a great deal of literature has studied the asymmetric effects of oil price shock on economic activity (see Mork, 1989; Hamilton, 1996; and Sadorsky, 1999).
} 
When testing for the asymmetry relating to the magnitude of oil price changes, we find that stock return sensitivities are significantly higher for large oil variations in Oman and Qatar. These dissimilarities, in terms of stock market reactions, confirm that GCC countries still differ in their levels of dependency on oil, especially in their efforts to diversify their economies through structural reforms. Our research emphasizes the importance of accounting for differences in stock return sensitivities across GCC countries - including potential asymmetric mechanisms - when making portfolio diversification decisions and forming oil-price-related hedging strategies. Ongoing and expected structural reforms are important, insofar as they serve to reduce stock market returns' sensitivities to oil movements.

The paper proceeds as follows: Section 2 provides a short overview of GCC stock markets and discusses the role of oil. Section 3 presents the data and their statistical properties, and Section 4 describes the econometric methodology. Section 5 is devoted to the empirical results, and Section 6 discusses several policy implications for the GCC region. Finally, Section 7 offers some concluding remarks.

\section{GCC Stock Markets AND Oil Prices}

The GCC region holds 30 percent of the world's crude oil proven reserves and represented roughly 34 percent of world oil exports in 2016. ${ }^{5}$ GCC countries share similar economic and political characteristics, but Bahrain, for example, is less reliant on oil than Saudi Arabia and Kuwait. Oil rents (difference between the price of crude oil production and total cost of production) range from 2.6 percent of GDP for Bahrain to 38.5 percent of GDP for Kuwait, totaling \$255 billion in oil rents for the region (18.3 percent of GDP) in 2015 (see Figure 1). Petrodollar accumulation, with the oil price nearly tripling from $\$ 50$ in early 2007 to $\$ 147$ before the global financial crisis (GFC), began to take hold in late 2008. This situation, along with the global investment of their sovereign wealth funds, and important economic reforms, such as financial liberalization, has given GCC countries greater exposure to international markets.

\section{Figure 1. Brent Oil Prices vs. GCC Oil Rents}

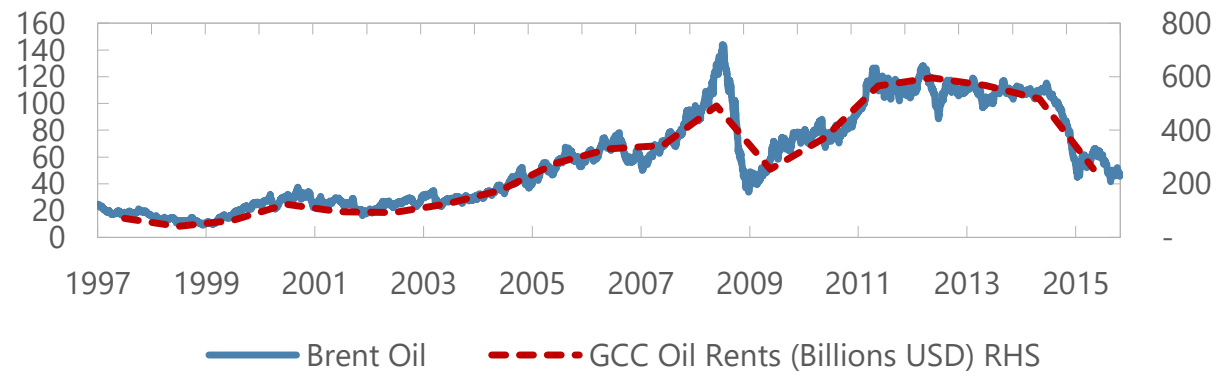

Source: Data are obtained from the EIA and the World Bank.

\footnotetext{
${ }^{5}$ Data for crude oil proven reserves are from the US Energy Information Administration (EIA). Crude oil export statistics are taken from The World Factbook.
} 
The first formal stock market in the GCC region was the Kuwait Stock Exchange, established in 1977. Saudi Arabia, Oman, and Bahrain established their own formal stock markets in the 1980s, followed by Qatar in the 1990s. ${ }^{6}$ The UAE brought the total number of stock exchanges in the GCC region to seven, with the opening of both the Dubai Financial Market and the Abu Dhabi Securities Exchange in $2000 .{ }^{7}$ In more recent years, GCC countries have loosened restrictions for foreign investors and implemented a wide range of legal, regulatory, and supervisory changes to strengthen market transparency. This financial liberalization has contributed to the further development of formal stock markets in the region. Figure 2 shows the rapid increase of listed companies from 2002 to 2015.

\section{Figure 2. GCC Stock Market: Listed Companies and Market Capitalization}

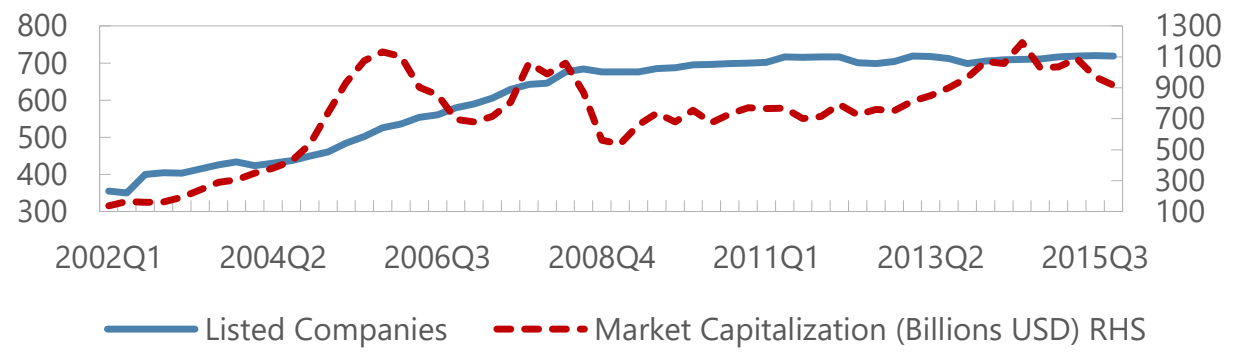

Source: Arab Monetary Fund.

The total market capitalization of GCC stock markets was \$916 billion in Q4 2015, an almost sevenfold increase from \$137 billion in Q1 2002 (see Table 1). Saudi Arabia’s stock market, the largest in the region, accounts for 46 percent of stock market capitalization in the GCC. The smallest stock market in the region is Bahrain's. In terms of total listed companies, Kuwait has the largest number with 216, followed by Saudi Arabia (172), and then Oman (131).

Table 1. GCC Markets in 2015

\begin{tabular}{lcccc}
\hline \hline & $\begin{array}{c}\text { Listed } \\
\text { companies }\end{array}$ & $\begin{array}{c}\text { Market } \\
\text { capitalization } \\
\text { (USD Millions) }\end{array}$ & $\begin{array}{c}\text { GDP } \\
\text { (USD } \\
\text { Millions) }\end{array}$ & $\begin{array}{c}\text { Market } \\
\text { cap./GDP }\end{array}$ \\
\hline Bahrain & 46 & 19.093 & 31.126 & 0.61 \\
Kuwait & 216 & 87.767 & 114.041 & 0.77 \\
Oman & 131 & 40.984 & 69.831 & 0.59 \\
Qatar & 42 & 151.892 & 164.641 & 0.92 \\
Saudi Arabia & 172 & 420.656 & 646.002 & 0.65 \\
UAE & 127 & 195.776 & 370.296 & 0.53
\end{tabular}

Notes: All figures were obtained from the Arab Monetary Fund and the World Bank.

\footnotetext{
6 The Saudi stock market, known as the Tadawul, was mostly informal throughout the 1970 s, with only 14 companies listed, but in 1984, the government created a ministerial committee to develop and regulate the market. In 2003, the government created the Capital Market Authority (CMA), the sole regulator of the market, and in 2007, the Saudi Stock Exchange (Tadawul) Company was formed.

${ }^{7}$ Saudi Arabia was the first country in the Gulf region to launch a parallel market, called Nomu (meaning "growth" in Arabic), which was established on February 26, 2017.
} 


\section{Data And Their Properties}

\section{A. Data Description}

This study examines the asymmetrical effects of oil price fluctuations on stock returns for six GCC countries: Bahrain, Kuwait, Oman, Qatar, Saudi Arabia, and the UAE. We select monthly data spanning the period of January 2004-December 2015, except for Kuwait, where data are only available starting from May $2005 .^{8}$

As for oil data, we use the monthly Brent spot prices to analyze the international crude oil market. Oil prices are denominated in US dollars and available from the US Energy Information Administration (EIA). We compute oil returns using the first logarithmic difference of oil prices, or $_{t} .{ }^{9}$ The stock market data are national stock price indices for the six GCC countries, expressed in US dollars, gathered from the Morgan Stanley Capital International (MSCI) database. ${ }^{10}$ We use monthly returns, defined as the first logarithmic differences of monthly stock price indices $\left(s r_{t}\right)$. In addition, we include the monthly MSCI World Index returns, $w r_{t}$, and the US three-month treasury bill (T-bill) interest rate, $i_{t}^{u s}$, as control variables for the empirical relationship between oil price and the stock market. The MSCI World Index and the US three-month T-bill interest rate are among the global factors that strongly influence GCC stock markets. ${ }^{11}$ Since GCC global investors consider both local and world markets, GCC stock markets can be affected by World Index fluctuations. The US interest rate is used here as a proxy for the GCC interest rate, since GCC monetary policies follow US monetary policy, due to the links between their national currencies and the US dollar. These financial data are obtained from the MSCI database.

Compared to previous studies (see Arouri and Rault, 2012; Akoum et al., 2012; and Mohanty et al., 2011), our sample period is, to some extent, shorter, but more recent, which allows us to cover some major events, such as the spectacular increases in oil prices throughout 2007 and early 2008, as well as the dramatic change in the financial environment since the eruption of the subprime crisis in the summer of 2007. ${ }^{2}$ Also, as reported in Figure 3, after

\footnotetext{
${ }^{8}$ Several empirical studies consider high-frequency data when investigating oil-stock-prices nexus. In fact, as recommended by Teräsvirta (1998), the quality of the estimated STR models should be checked against misspecification at the evaluation stage. Then, the selected STR models should pass the main diagnostic tests; there should be no error autocorrelation, no ARCH effect, parameter constancies, and no remaining nonlinearity. Since daily or weekly time series would probably exhibit ARCH effects, implementing STR models would be inappropriate.

${ }^{9}$ To check for robustness, we employ other crude oil benchmarks, i.e., West Texas Intermediate (WTI) and OPEC spot prices. These oil prices did not significantly alter the results of our benchmark specifications.

${ }^{10}$ Stock price series are expressed in US dollars to gauge their homogeneous features consistently, and to avoid the impacts of currency risks on empirical results.

${ }^{11}$ Other global factors are considered in the literature to control for the oil-stock-prices nexus. For example, Arouri et al. (2014) have accounted for the risks associated with economic policy changes in developed countries (USA and Europe), and how they might spillover into GCC stock markets. The authors rely on the indices of economic policy uncertainty (EPU), as proposed by Baker et al. (2016). For instance, the EPU index constructed for the US economy strongly correlates with our control variables, the MSCI global index, and the three-month US T-bill.

${ }^{12}$ Due to lack of data availability, our study does not cover the very recent episode of political tensions in the GCC region.
} 
nearly five years of stability from 2010 to mid-2014, the Brent crude oil price has fallen to its lowest level in 10 years. The time series plots of our six stock price indices reveal that the oil-boom-bust cycle of 2007-2009_compounded by the spillover of the subprime crisishas strongly impacted the GCC stock market. Significantly, the log levels of GCC stocks and Brent oil prices plotted in Figure 3 show common trending behaviors, which may be indicative of some interdependence between all markets. Over the same period, the stock market indices in GCC countries continue to increase (decrease) as oil prices continue to rise (fall).

Figure 3. GCC Stock Market Indices and Brent Oil Prices over the Last Decade

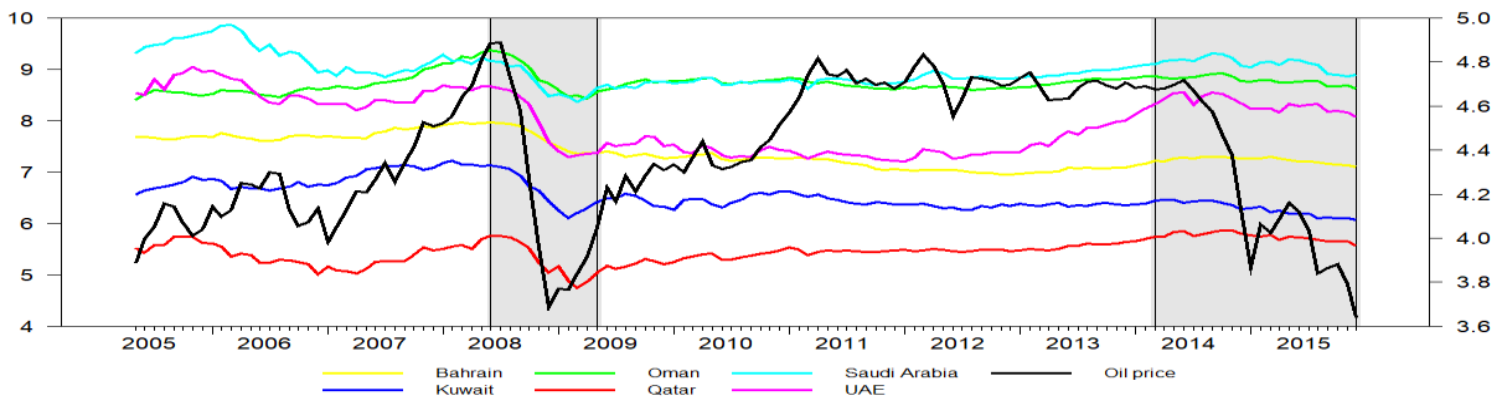

Note: Data are monthly log levels of GCC stocks and Brent oil prices. Data are obtained from the EIA and MSCI database.

Table 2 presents some summary statistics on stock market indices and oil returns over 20042014. For example, monthly average returns on Bahrain's and Kuwait's national stock markets are negative throughout our sample, which may indicate the effect of the oil price decline in late 2008, as well as that of the recent 2007-2009 GFC. For the rest of our GCC countries, we document positive average stock returns, with the UAE market showing the best performance ( 0.81 percent). Only Qatar's and the UAE's stock markets have performed better than the global equity market proxied by the MSCI World Index (0.65 percent). When excluding the turbulent year of 2006, Saudi Arabia's monthly average stock return becomes comparable to the UAE's (about 0.79). At the same time, Qatari and Emirati markets are shown to have recorded the highest variabilities as measured by the standard deviation. Table 2 also reveals a positive average return of 0.13 percent for the Brent oil prices, as well as a higher volatility rate, which may be due to the past decade's boom-bust in oil prices.

Table 2. Descriptive Statistics for Stock and Crude Market Returns

\begin{tabular}{lcccc}
\hline \hline & Mean (\%) & Min. (\%) & Max. (\%) & Std. Dev. \\
\hline Stock prices & -0.04 & -12.15 & 10.35 & 0.04 \\
$\quad$ Bahrain & -0.39 & -21.12 & 19.08 & 0.07 \\
Kuwait & 0.50 & -25.76 & 15.93 & 0.05 \\
Oman & 0.68 & -28.83 & 39.61 & 0.09 \\
Qatar & 0.36 & -25.38 & 18.02 & 0.08 \\
Saudi Arabia & 0.81 & -38.66 & 35.61 & 0.11 \\
UAE & 0.13 & -31.10 & 19.60 & 0.09 \\
Brent oil prices & 0.65 & -32.16 & 15.41 & 0.07 \\
MSCI World Index & P & &
\end{tabular}

Note: Data are monthly returns on stock market indices and oil prices using first log differences of monthly series. Data are obtained from the EIA and MSCI database. 
We also compute the pairwise return correlations for all pairs of indices in our sample, as reported in Table 3. Of the six GCC countries, the highest positive correlation is found between the Qatar and UAE stock indices (0.63). Bahrain and Kuwait share the lowest correlation coefficient (0.29). We note that the country pairs Bahrain/Qatar, Oman/Qatar, and Oman/UAE each exhibit the same positive correlation coefficient of 0.55 . This is not surprising, as the major GCC stock markets were engaged in several financial liberalization reforms in the 1990s. These relationships, resulting from the interdependence between national stock indices and the MSCI Global Index, are positive and vary from 0.04 (Bahrain/world) to 0.45 (Kuwait/world). Evidently, Kuwait is more sensitive to global factors than (the) other GCC countries. This could be seen as higher sensitivity to global factors in comparison to the rest of GCC group.

Very similar comovements are observed between the Brent oil index and the national stock indices across most GCC countries. Each correlation coefficient is close to 0.40, except for Bahrain (0.18), suggesting that GCC stock markets move jointly with oil prices.

Nevertheless, the positive correlations between national stock markets are, in general, higher than those between national equity returns and oil markets, indicating that GCC stock markets are significantly integrated with one another. Finally, the US three-month treasury bill's interest rate, as a global factor, seems to influence GCC stock markets weakly. The same positive relationship is found in each country in the GCC region, but does not exceed 0.16 as a correlation coefficient.

Table 3. Cross-Correlation Coefficients Among Stock Markets and Oil Returns

\begin{tabular}{lccccccccc}
\hline \hline & Bahrain & Kuwait & Oman & Qatar & Saudi Arabia & UAE & Brent oil & MSCI Index & US T-bill \\
\hline Bahrain & 1.00 & & & & & & & & \\
Kuwait & 0.29 & 1.00 & & & & & & & \\
Oman & 0.58 & 0.36 & 1.00 & & & & & & \\
Qatar & 0.55 & 0.32 & 0.55 & 1.00 & & & & & \\
Saudi Arabia & 0.41 & 0.24 & 0.49 & 0.52 & 1.00 & & & & \\
UAE & 0.59 & 0.31 & 0.55 & 0.63 & 0.57 & 1.00 & & & \\
Brent oil & 0.18 & 0.35 & 0.40 & 0.35 & 0.37 & 0.36 & 1.00 & & \\
MSCI Index & 0.04 & 0.45 & 0.21 & 0.13 & 0.13 & 0.09 & 0.38 & 1.00 & \\
US T-bill & 0.02 & 0.16 & 0.05 & 0.10 & 0.08 & 0.08 & 0.18 & 0.23 & 1.00 \\
\hline \hline
\end{tabular}

Note: The table reports correlation coefficients for six GCC stock returns (Bahrain, Kuwait, Oman, Qatar, Saudi Arabia, and the UAE), the MSCI global return, and the Brent crude oil return. The sample period is between January 2004 and December 2015, except for Kuwait, where data are only available starting from May 2005.

\section{B. Unit Root Tests}

We examine the properties of our key variables by checking stationarity. We test for the presence of unit roots in the levels (price series in logarithm) and first differences (return series) of oil and stock market price indices. ${ }^{13}$ We perform the DF-GLS test, proposed by Elliott et al. (1996), which is an augmented Dickey-Fuller test, where the time series is transformed via a generalized least squares (GLS) regression before the test is performed.

\footnotetext{
${ }^{13}$ Interest rates are in percentages; therefore, the logarithm is defined as $\log (1+r / 100)$.
} 
Elliott et al. (1996) have shown that this test has significantly greater power than the previous versions of the augmented Dickey-Fuller approach. Since our study period covers episodes of high fluctuations in oil and stock markets, structural changes would occur in the oil and stock return series. Thus, a DF-GLS unit root test might not be powerful in the presence of a structural break in the considered series. To check whether our unit root test results are robust to the presence of potential structural breaks, we implement Zivot and Andrews's (1992) ZA test and Lumsdaine and Papell's (1997) LP test henceforth, these being unit root tests that allow for possible breaks in series. ${ }^{14}$ In constructing the unit root tests, the level variables were tested in the presence of both an intercept and a trend. The subsequent tests of first differences each include only an intercept, given the lack of trending behavior in the first difference series.

Summary results of these statistical tests for both price and return series are reported in Table 4. Our findings show that, when using DF-GLS unit root tests, the null hypothesis of a unit root cannot be rejected for all variables across levels, except for the US three-month treasury bill. In fact, there was a dramatic fall in US interest rates following the recent financial crisis, which may indicate the presence of structural changes in the data. Hence, when using ZA and LP unit root tests, the US three-month treasury bill series are found to be nonstationary. For variables in first log differences, all unit root tests suggest that we should reject the null hypothesis of nonstationarity.

Table 4. Unit Root Tests

\begin{tabular}{|c|c|c|c|c|c|c|}
\hline & \multicolumn{2}{|c|}{ DF-GLS test } & \multicolumn{2}{|c|}{ ZA test } & \multicolumn{2}{|c|}{ LP test } \\
\hline & level & $1^{\text {st }}$ diff. & level & $1^{\text {st }}$ diff. & level & $1^{\text {st }}$ diff. \\
\hline \multicolumn{7}{|l|}{ Stock prices } \\
\hline Bahrain & -4.290 & $-6.299 * * *$ & -4.290 & $-6.299 * * *$ & -5.469 & $-6.662 * *$ \\
\hline Kuwait & -4.697 & $-6.031 * * *$ & -4.697 & $-6.031 * * *$ & -5.508 & $-6.560 * *$ \\
\hline Oman & -3.802 & $-5.701 * * *$ & -3.802 & $-5.701 * * *$ & -4.555 & $-5.927^{*}$ \\
\hline Qatar & -4.061 & $-9.801 * * *$ & -4.061 & $-9.801 * * *$ & -4.208 & $-10.125^{* * *}$ \\
\hline Saudi Arabia & -3.584 & $-11.074 * * *$ & -3.584 & $-11.074 * * *$ & -4.502 & $-11.580 * * *$ \\
\hline$U A E$ & -4.518 & $-6.694 * * *$ & -4.518 & $-6.694 * * *$ & -5.067 & $-6.980 * * *$ \\
\hline Brent oil prices & -1.501 & $-5.607 * * *$ & -1.761 & $-6.582 * * *$ & -2.645 & $-6.681^{*}$ \\
\hline MSCI World Index & -1.866 & $-4.226 * * *$ & -3.167 & $-10.958 * * *$ & -3.614 & $-11.172 * *$ \\
\hline US T-bill & $-2.043 * *$ & $-5.302 * * *$ & -3.623 & $-7.292 * * *$ & -5.165 & $-8.114^{* *}$ \\
\hline
\end{tabular}

Note: DF-GLS, ZA (Zivot and Andrews, 1992), and LP (Lumsdaine and Papell, 1997) tests are performed using $\log$ prices and return series. *, **, and $* * *$ denote rejection of the null hypothesis at the $10 \%, 5 \%$, and $1 \%$ levels, respectively. The ZA test allows for one single break under the alternative hypothesis. The LP test allows for two structural breaks under the alternative hypothesis. Lag selection: Akaike (AIC). Maximum lag number $=$ 8.

\footnotetext{
${ }^{14}$ In the ZA and LP unit root tests, break dates are endogenously determined within the models. The ZA test allows for one single break under the alternative hypothesis. The LP test is an extension of the Zivot and Andrews (1992) model, allowing for two structural breaks under the alternative hypothesis.
} 


\section{EMPIRICAL METHODOLOGY}

\section{A. Econometric Model}

Several studies suggest the presence of nonlinear links between oil and economic activity (see Mork, 1989, and Hamilton, 1996). Oil price increases are found to be much more influential than oil price decreases, indicating an asymmetric relationship between oil price and output level. More recently, several papers have examined the potential asymmetric relationships between the crude oil market and other asset prices, such as stock prices or stock returns. For example, Bittlingmayer (2005) found that oil price changes stemming from war risks, and those related to other causes, exhibit asymmetric effects on stock price dynamics.

In fact, ignoring nonlinearity can lead to problematic results. Balcilar et al. (2015) argue that using a linear framework would lead to mixed results, with an unexpected positive relationship between US crude oil and stock market prices. The authors have considered the asymmetric effects of positive and negative oil price shocks on stock returns by using Granger and Yoon's (2002) concept of hidden cointegration. Balcilar et al. (2015) provide strong evidence of asymmetry, with negative oil price shock exerting a positive, larger effect. However, the result is counterintuitive for positive oil shocks, since they do not reduce stock prices. Moreover, some ad hoc methods have been implemented to differentiate between stock market responses to oil price increases and stock market responses to falling oil prices. For example, Mohanty et al. (2011) introduce a dummy variable to capture the asymmetry with respect to oil price decrease and increase in a sample of GCC countries. The dummy variable takes the value of unity if the change in the oil price is positive, and zero otherwise. While declines in oil prices negatively impact all GCC stock markets, Mohanty et al. (2011) reveal that oil price increases have mixed effects on stock returns.

In this paper, we adopt a different econometric approach, based on the implementation of regime-switching models, where it is possible to model two sources of asymmetry. On the one hand, we analyze the asymmetric effects of positive and negative oil price variations on stock returns. On the other hand, we check whether large shocks have more pronounced effects than small ones. We use a class of nonlinear regime-switching models, namely, STR models. ${ }^{15}$ The STR model takes the following general form:

$$
y_{t}=\theta_{1} x_{t}+\theta_{2} x_{t} G\left(s_{t} ; \gamma, c\right)+u_{t}
$$

where $u_{t} \sim \operatorname{iid}\left(0, \sigma^{2}\right)$, and $\theta_{1}$ and $\theta_{2}$ are linear and nonlinear coefficients, respectively. $G\left(s_{t} ; \gamma, c\right)$ is the transition function that controls the nonlinear dynamic of the STR model. $G\left(s_{t} ; \gamma, c\right)$ is a continuous function bounded between 0 and 1 , depending on the value of the transition variable $s_{t}$; the speed of transition across regimes, $\gamma$; and the threshold level (or location parameter), $c$. A popular choice for the transition function is the logistic specification that is given by

\footnotetext{
15 The univariate case of the STR model is known as the smooth transition autoregressive (STAR) model (see Teräsvirta, 1994).
} 


$$
G\left(s_{t} ; \gamma, c\right)=\left[1+\exp \left\{-\gamma\left(s_{t}-c\right)\right\}\right]^{-1}
$$

Under the logistic transition function, equation (1) corresponds to the LSTR model. The implied nonlinear dynamics of the LSTR specification depend on whether the transition variable is below or above the threshold level $c$. In other words, the parameters of the model change monotonically from $\theta_{1}$ to $\left(\theta_{1}+\theta_{2}\right)$ as $s_{t}$ increases. Indeed, if $\left(s_{t}-c\right) \rightarrow-\infty$, and $G\left(s_{t} ; \gamma, c\right) \rightarrow 0$, the model's coefficient corresponds to $\theta_{1}$. If $\left(s_{t}-c\right) \rightarrow+\infty$. If $G\left(s_{t} ; \gamma, c\right) \rightarrow$ 1 , the coefficient becomes $\left(\theta_{1}+\theta_{2}\right)$. Finally, if $s_{t}=c$, and $G\left(s_{t} ; \gamma, c\right)=0.5$, the coefficient will be equal to $\left(\theta_{1}+\theta_{2} / 2\right)$.

Another popular choice of the transition function, which is often used in the literature, is the exponential specification

$G\left(s_{t} ; \gamma, c\right)=1-\exp \left\{-\gamma\left(s_{t}-c\right)^{2}\right\}$

where the pattern formed jointly by equations (1) and (3) is called the ESTR model. The implied nonlinear dynamics are drastically different under exponential and logistic functions. In the ESTR model, the dynamic is symmetric with respect to the negative or positive deviations of $s_{t}$ from the threshold level. The exponential form is appropriate in situations where the dynamic behavior is different for large and small values of $s_{t}$. What matters is the magnitude or the size of the shock, i.e., whether it is large or small. Thus, the parameters of the model change depending on whether $s_{t}$ is close to or far away from the threshold, $c$, regardless of whether the difference $\left(s_{t}-c\right)$ is positive or negative. As $\left(s_{t}-c\right) \rightarrow \pm \infty$, if the exponential transition function is $G\left(s_{t} ; \gamma, c\right) \rightarrow 1$, the model coefficients will be equal to $\left(\theta_{1}+\theta_{2}\right)$. If $s_{t}=c$, then $G\left(s_{t} ; \gamma, c\right) \rightarrow 0$, and the coefficients will correspond to $\theta_{1}$.

Since LSTR and ESTR models allow for different nonlinear behaviors, we must be careful when implementing these specifications in our analyses of oil price changes' impacts on stock returns. The use of LSTR would be appropriate in accounting for asymmetry with respect to the direction of oil price change, (the asymmetry between negative or positive oil shocks), especially when the threshold value is close to zero $c \simeq 0 .{ }^{16}$ On the other hand, the exponential form would be more useful in capturing asymmetry with respect to the magnitude of oil price change, that is, whether an oil shock is small or large.

\section{B. Empirical Specification}

In our study, we consider the following nonlinear STR model in order to investigate the asymmetric effects of oil price changes on stock markets:

$s r_{t}=\alpha+\sum_{j=1}^{N} \lambda_{j} s r_{t-j}+\sum_{j=0}^{N} \psi_{j} w r_{t-j}+\sum_{j=0}^{N} \delta_{j} i_{t-j}^{u s}$

${ }^{16}$ LSTR models have frequently been implemented for modelling business cycles. By considering an indicator of economic activity as a transition variable, the logistic model enables us to distinguish between periods of positive and negative economic growth, i.e., between expansions and contractions (see van Dijk et al., 2002). 


$$
+\sum_{j=0}^{N} \beta_{j} o r_{t-j}+\left(\sum_{j=0}^{N} \phi_{j} o r_{t-j}\right) G\left(s_{t} ; \gamma, c\right)+\varepsilon_{t}
$$

where oil return is used as a transition variable $\left(s_{t}=o r_{t-j}\right)$. All variables included in equation (4) are return series and, as discussed above, are stationary in first differences. ${ }^{17}$ According to equation (4), the long-run impact of oil price change is given by the following time-varying coefficients: $\left[\sum_{j=0}^{N} \beta_{j}+\sum_{j=0}^{N} \phi_{j} G\left(s_{t} ; \gamma, c\right)\right] /\left[1-\sum_{j=1}^{N} \lambda_{j}\right] .{ }^{18}$

As we experiment with both transition functions, $G\left(s_{t} ; \gamma, c\right)$ takes the form of a logistic or exponential function. For the LSTR specifications, the effects of oil prices on stock markets takes different values depending on whether the transition variable $o r_{t-j}$ is below or above threshold of $c \simeq 0$. If $\left(o r_{t-j}-c\right) \rightarrow-\infty$ (for a negative oil shock), the impact on stock price corresponds to $\sum_{j=0}^{N} \beta_{j} /\left(1-\sum_{j=1}^{N} \lambda_{j}\right)$. If $\left(o r_{t-j}-c\right) \rightarrow+\infty$ (for a positive oil shock), oil effect becomes $\left(\sum_{j=0}^{N} \beta_{j}+\sum_{j=0}^{N} \phi_{j}\right) /\left(1-\sum_{j=1}^{N} \lambda_{j}\right)$. In the case of the ESTR model, oil price change's impact depends on whether $0 r_{t-j}$ is close to or far away from the threshold $c$, regardless of whether the difference $\left(o_{t-j}-c\right)$ is positive or negative. Therefore, if $\left(\right.$ or $\left._{t-j}-c\right) \rightarrow \pm \infty$ (for a large oil shock), the effect on the stock market will be equal to $\left(\sum_{j=0}^{N} \beta_{j}+\sum_{j=0}^{N} \phi_{j}\right) /\left(1-\sum_{j=1}^{N} \lambda_{j}\right)$. If $o r_{t-j}=c$ (for a small oil shock), oil price's impact becomes $\sum_{j=0}^{N} \beta_{j} /\left(1-\sum_{j=1}^{N} \lambda_{j}\right)$.

We first use the STR model to test for nonlinearity, in order to select the appropriate lagged oil return as a threshold variable, and the most suitable form of the transition function, namely, the logistic or exponential specification. The linearity tests are conducted for each lagged oil return, $o r_{t-j}$, with $j=1, \cdots, 6$. Next, the parameters of our STR equation (4) are estimated using the nonlinear least squares (NLS) estimation technique, which provides estimators that are consistent and asymptotically normal. In the final step, we check the quality of our estimated model using some misspecification tests. Of the most frequently used tests in the STR literature, we implement the Lagrange Multiplier (LM) test of no error autocorrelation, an LM-type test of no ARCH, the LM test of no remaining nonlinearity, and an LM-type test of parameter constancy. ${ }^{19}$

\footnotetext{
${ }^{17}$ As variables in levels are integrated of order one, we have tested for the presence of a possible long-run relationship. We have implemented Gregory and Hansen's (1996) cointegration test, which explicitly incorporates a break in the cointegrating relationship. Our results reveal that a long-run cointegrating "cointegrated" relationship exists only for Saudi Arabia. However, this finding is not robust to a modification of the significance level considered. Results from Gregory and Hansen's (1996) cointegration tests are not reported here in order to save space, but are available upon request. Note that the first differences variables (return series) are considered here when estimating the impacts of oil prices on stock prices for all GCC countries, as in equation (4).

${ }^{18}$ Following van Dijk et al. (2002), the lag lengths of the variables entering equation (4) are determined by adopting a general-to-specific approach to select the final specifications. We start with a model with a maximum lag length of $N=6$, and then sequentially drop the lagged variables for which the $t$-statistic of the corresponding parameter is less than 1.0 in absolute value.

${ }^{19}$ See Eitrheim and Teräsvirta (1996) for a detailed discussion of misspecification tests.
} 


\section{EMPIRICAL RESUlts}

Over the last decade, oil prices and stock prices have been very volatile following the Global Financial Crisis (GFC). These have revived the theory that there is a nonlinear relationship between oil and stock prices. In this paper, we investigate the presence of asymmetric behaviors on the impacts of oil prices on GCC stock markets. We imagine that a nonlinear model is more appropriate to account for structural instability, and to capture the existence of potential asymmetry. As discussed above, there are two types of asymmetry that can be modeled using nonlinear STR models. On the one hand, asymmetry may arise with respect to a shift in the direction of oil price change (difference between negative and positive oil shocks). On the other hand, there is a second type of asymmetry related to the magnitude of oil prices shocks (whether oil prices changes are small or large).

Following the modelling strategy of Teräsvirta $(1994,1998)$, we begin by conducting linearity tests to select the appropriate lagged transition variable $o r_{t-j}$. Also, no remaining nonlinearity tests are conducted after the estimation of our choice of transition variable. The transition variables to be selected should provide the strongest rejection of both the null of linearity (against the STR alternative), and of the lack of additive nonlinearity, after the estimation of the nonlinear model's estimation ${ }^{20}$ As reported in Table 5, linearity tests reveal strong evidence for the presence of nonlinearity in our six GCC countries, except for the UAE. Accordingly, there is potential asymmetry in the transmission of oil price change to the stock market. Once linearity has been rejected, the next step is to employ the sequence of the null hypotheses for selecting the relevant transition function (logistic or exponential). In Table 5, the best specifications, in terms of rejection of linearity, and of no additive nonlinearity, are indicated in bold.

As discussed in the STR literature, the increases in computational power have made the decision rule - which is based on testing a sequence of nested null hypotheses-less important in practice (van Dijk et al., 2002). Therefore, it would be more convenient to estimate both LSTR and ESTR models and choose between them at the evaluation stage by implementing misspecification tests. In addition, economic intuition must be considered in selecting the adequate transition function. In our study, we aim to explore the two possible sources of asymmetry with respect to both the direction and magnitude of oil price shock. Then, we estimate both LSTAR and ESTAR models for each of our GCC countries. This is a sensible way to determine what kind of asymmetry really drives the impact of oil price on the stock market. In each case, the best specification is selected with respect to the misspecification test (no error autocorrelation, no conditional heteroscedasticity, parameter constancy, and no remaining nonlinearity).

\footnotetext{
${ }^{20}$ The Saudi stock market experienced a rigorous crash in 2006 after the stock price index collapsed, losing roughly 65 percent of its value. This could possibly be considered an outlier when conducting linearity tests. To check for robustness, we have tested for smooth transition nonlinearity by adjusting for outliers using iterated weighted least squares, as in van Dijk et al. (1999). The obtained results are quite similar to those reported in Table 5. To save space, the results are not reported here, but are available upon request.
} 
Table 5. Linearity Tests

\begin{tabular}{|c|c|c|c|c|c|c|}
\hline Country & Transition variable & $H_{0}$ & $H_{04}$ & $H_{03}$ & $H_{02}$ & Specification \\
\hline \multirow[t]{6}{*}{ Bahrain } & $o r_{t-1}$ & 0.035 & 0.142 & 0.399 & 0.006 & LSTR \\
\hline & $o r_{t-2}$ & 0.576 & 0.985 & 0.205 & 0.014 & Linear \\
\hline & $o r_{t-3}$ & 0.377 & 0.926 & 0.237 & 0.005 & Linear \\
\hline & $o r_{t-4}$ & 0.012 & 0.054 & 0.639 & 0.001 & LSTR \\
\hline & $o r_{t-5}$ & 0.581 & 0.935 & 0.313 & 0.035 & Linear \\
\hline & or $_{t-6}$ & 0.000 & 0.003 & 0.015 & 0.065 & LSTR \\
\hline \multirow[t]{6}{*}{ Kuwait } & $o r_{t-1}$ & 0.226 & 0.316 & 0.125 & 0.651 & Linear \\
\hline & $o r_{t-2}$ & 0.020 & 0.328 & 0.029 & 0.006 & LSTR \\
\hline & $o r_{t-3}$ & 0.477 & 0.457 & 0.684 & 0.220 & Linear \\
\hline & $o r_{t-4}$ & 0.005 & 0.051 & 0.057 & 0.023 & LSTR \\
\hline & $o r_{t-5}$ & 0.186 & 0.245 & 0.700 & 0.041 & Linear \\
\hline & $o r_{t-6}$ & 0.063 & 0.220 & 0.024 & 0.486 & Linear \\
\hline \multirow[t]{6}{*}{ Oman } & $o r_{t-1}$ & 0.003 & 0.251 & 0.002 & 0.025 & ESTR \\
\hline & $o r_{t-2}$ & 0.346 & 0.887 & 0.684 & 0.001 & Linear \\
\hline & $o r_{t-3}$ & 0.010 & 0.083 & 0.020 & 0.225 & ESTR \\
\hline & $o r_{t-4}$ & 0.011 & 0.203 & 0.006 & 0.164 & ESTR \\
\hline & $o r_{t-5}$ & 0.062 & 0.285 & 0.007 & 0.756 & Linear \\
\hline & or $_{t-6}$ & 0.024 & 0.056 & 0.080 & 0.382 & LSTR \\
\hline \multirow[t]{6}{*}{ Qatar } & $o r_{t-1}$ & 0.115 & 0.155 & 0.143 & 0.562 & Linear \\
\hline & $o r_{t-2}$ & 0.001 & 0.025 & 0.016 & 0.024 & ESTR \\
\hline & $o r_{t-3}$ & 0.001 & 0.241 & 0.000 & 0.039 & ESTR \\
\hline & $o r_{t-4}$ & 0.000 & 0.287 & 0.005 & 0.000 & LSTR \\
\hline & $o r_{t-5}$ & 0.004 & 0.122 & 0.151 & 0.001 & LSTR \\
\hline & $o r_{t-6}$ & 0.096 & 0.585 & 0.171 & 0.008 & LSTR \\
\hline \multirow[t]{6}{*}{ Saudi Arabia } & $o r_{t-1}$ & 0.197 & 0.629 & 0.378 & 0.011 & Linear \\
\hline & $o r_{t-2}$ & 0.037 & 0.157 & 0.030 & 0.394 & ESTR \\
\hline & $o r_{t-3}$ & 0.033 & 0.378 & 0.001 & 0.613 & ESTR \\
\hline & $o r_{t-4}$ & 0.029 & 0.185 & 0.039 & 0.154 & ESTR \\
\hline & $o r_{t-5}$ & 0.033 & 0.231 & 0.007 & 0.504 & ESTR \\
\hline & $o r_{t-6}$ & 0.001 & 0.004 & 0.143 & 0.040 & LSTR \\
\hline \multirow[t]{6}{*}{ UAE } & $o r_{t-1}$ & 0.778 & 0.521 & 0.992 & 0.212 & Linear \\
\hline & $o r_{t-2}$ & 0.443 & 0.522 & 0.242 & 0.580 & Linear \\
\hline & $o r_{t-3}$ & 0.275 & 0.153 & 0.742 & 0.414 & Linear \\
\hline & $o r_{t-4}$ & 0.780 & 0.833 & 0.383 & 0.585 & Linear \\
\hline & $o r_{t-5}$ & 0.460 & 0.329 & 0.591 & 0.597 & Linear \\
\hline & $o r_{t-6}$ & 0.334 & 0.214 & 0.384 & 0.851 & Linear \\
\hline
\end{tabular}

Note: Numbers are $p$-values of $F$-versions of the LM linearity tests. Third column shows the test of linearity against the alternative of STR nonlinearity. From the forth column until the sixth, we report the $p$-values of the sequential tests for choosing the adequate transition function. The decision rule is the following: If the test of $H_{03}$ yields the strongest rejection of the null hypothesis, we choose the ESTR specification. Otherwise, we select the LSTR model. The last column gives the selected model. 


\section{A. Asymmetry Between Positive and Negative Oil Price Changes}

We begin by investigating whether stock returns in GCC countries respond asymmetrically to oil price decreases and increases. To capture the asymmetry arising from the direction of oil price shock, we implement the LSTR specification, which is appropriate for separating oil price into positive and negative changes. We expect negative oil price changes to have larger impacts on stock returns than their positive counterparts (Sim and Zhou, 2015, and Mohanty et al., 2011). This is valid for oil-exporting countries. The higher sensitivity of stock returns to negative oil shocks can be explained by the lower corporate earnings caused by the decline in industrial production activity.

The NLS estimates of our LSTR equations are reported in Table 6. We indicate a coefficient for each of the two extreme regimes, namely, for negative oil shock when $G\left(s_{t} ; \gamma . c\right)=0$, and for positive oil shock when $G\left(s_{t} ; \gamma . c\right)=1$. Full results from all STR models are presented in Table A1 and Table A2 in the appendix. ${ }^{21}$ We compute the sum of the squared residual ratio, $S S R_{\text {ratio }}$, between the LSTR model and the linear specification, which provides a better fit for the nonlinear model. We also check the quality of the estimated LSTR models by conducting several misspecification tests. In most cases, the selected LSTR models pass the main diagnostic tests (no error autocorrelation, no conditional heteroscedasticity, parameter constancy, and no remaining nonlinearity). ${ }^{22}$ In Table 6 , we provide results only for countries for which linearity is rejected, specifically, all GCC countries except the UAE.

The results related to the asymmetries between the impacts of oil price increases and decreases on stock returns in GCC countries are summarized as follows: According to Table 6 , the estimated threshold values of oil returns are highly significant for all GCC countries, except Saudi Arabia. Also, they are quite similar for the pairs Bahrain/Kuwait (threshold of around $c \simeq-0.10$ ) and Oman/Qatar (threshold of around $c \simeq 0.10$ ).

As for the estimated long-run effects of oil price changes, we find that stock return responses are not statistically significant in Bahrain and Saudi Arabia across the two regimes (for negative and positive oil price changes). Moreover, Table 6 reveals that negative (or small positive) oil price changes have significant effects on the stock market returns of Kuwait, Oman, and Qatar. For instance, when an oil variation is below the threshold of 9 percent $(c \simeq 0.09)$, the response of Qatar's stock return to a 1 percent oil change is equal to 0.42 percent. For Oman, stock return increases by 0.59 percent for a negative or small oil price deviation, being below the threshold of 10 percent $(c \simeq 0.10)$. For Kuwait, when the oil return decreases by over 10 percent $(c=-0.10)$, the response of the stock return, following a 1 percent oil price change, is equal to 0.66 percent.

\footnotetext{
${ }^{21}$ Lags on MSCI World Index returns and US three-month T-bills are found to be statistically insignificant across different estimated models. Hence, we retain only contemporaneous coefficients on MSCI index. In this context, returns and the three-month T-bill in the selection of our final specification.

${ }^{22}$ The best selected specifications in Tables 6 and 7 are, to some extent, different from those indicated by the sequential linearity tests in Table 5. As explained above, at this stage of estimation, the best specification is selected with respect to the misspecification test (no error autocorrelation, no conditional heteroscedasticity, parameter constancy, and no remaining nonlinearity).
} 
It is important to note that only Kuwait shows a significant reaction to stock price (about 0.33 percent), when oil price change is above the estimated threshold, such as when oil shock is positive (or slightly negative, with a decrease of less than 10 percent). According to Table 6, Kuwait's stock market exposure to oil price change is significantly unequal across the two regimes. When oil price changes are higher than the estimated thresholds in Oman and Qatar, the responses of stock price returns are weak and insignificant.

Table 6. Estimated Impacts of Oil Returns on GCC Stock Markets Using LSTR Specifications

\begin{tabular}{|c|c|c|c|c|c|}
\hline & Bahrain & Kuwait & Oman & Qatar & Saudi Arabia \\
\hline Transition variable $\left(s_{t}\right)$ & $o r_{t-4}$ & $o r_{t-4}$ & $o r_{t-6}$ & $o r_{t-6}$ & $o r_{t-3}$ \\
\hline \multirow[t]{2}{*}{ Threshold $(c)$} & $-0.095 * * *$ & $-0.100 * * *$ & $0.099 * * *$ & $0.091 * * *$ & 0.040 \\
\hline & $(0.019)$ & $(0.012)$ & $(0.019)$ & $(0.011)$ & $(0.034)$ \\
\hline \multirow[t]{2}{*}{ Speed of transition $(\gamma)$} & 6.766 & 8.654 & 7.341 & 14.052 & 4.032 \\
\hline & $(7.401)$ & $(13.941)$ & $(5.747)$ & $(16.130)$ & $(4.492)$ \\
\hline \multicolumn{6}{|c|}{ Negative oil changes: $G\left(s_{t} ; \gamma \cdot c\right)=0$} \\
\hline \multirow[t]{2}{*}{ Long-run effect } & 0.116 & $0.663 * * *$ & $0.587 * * *$ & $0.419 * * *$ & 0.418 \\
\hline & $(0.406)$ & $(0.161)$ & $(0.166)$ & $(0.132)$ & $(0.286)$ \\
\hline \multicolumn{6}{|c|}{ Positive oil changes: $G\left(s_{t} ; \gamma . c\right)=1$} \\
\hline \multirow[t]{2}{*}{ Long-run effect } & -0.108 & $0.330 * *$ & 0.133 & 0.220 & 0.178 \\
\hline & $(0.168)$ & $(0.159)$ & $(0.361)$ & $(0.509)$ & $(0.484)$ \\
\hline$R^{2}$ & 0.464 & 0.422 & 0.402 & 0.444 & 0.458 \\
\hline$S S R_{\text {ratio }}$ & 0.715 & 0.700 & 0.693 & 0.683 & 0.716 \\
\hline$p L M_{A R(6)}$ & 0.488 & 0.654 & 0.351 & 0.937 & 0.923 \\
\hline$p L M_{A R C H(6)}$ & 0.539 & 0.805 & 0.984 & 0.358 & 0.007 \\
\hline$p L M_{C}$ & 0.547 & 0.276 & 0.387 & 0.343 & 0.295 \\
\hline$p L M_{R N C}$ & 0.397 & 0.237 & 0.339 & 0.268 & 0.226 \\
\hline
\end{tabular}

Note: Table reports the impacts of oil price changes on GCC stock returns over 2004-2015. Results are obtained from the STR equation (4) using the LSTR. Numbers in parentheses are the standard errors. *,**, and *** denote significance at the $10 \%, 5 \%$, and $1 \%$ levels, respectively. $R^{2}$ denotes the coefficient of determination. $S S R_{\text {ratio }}$ is the ratio of the sum of squared residuals between the LSTR model and the linear specification. The following rows correspond to the misspecification tests: $p L M_{A R(6)}$ is the $p$-value of the LM test of no error autocorrelation up to the sixth order. $p L M_{A R C H(6)}$ is the $p$-value of the LM test of no ARCH effects up to the sixth order. $p L M_{C}$ is the $p$-value of the LM test of parameter constancy, and $p L M_{R N C}$ is the $p$ value of the LM test of no remaining nonlinearity.

To clarify the picture in Kuwait's case, we plotted both the estimated logistic functions and the stock return responses as functions of lagged oil returns $\left(s_{t}=o r_{t-j}\right)$ in Figure 4. ${ }^{23}$

The plotted logistic transition function is an increasing function of the transition variable $s_{t}=$ $o r_{t-j}$, and is obtained using the estimated values of $\hat{c}$ and $\hat{\gamma}$ as $G\left(o r_{t-j} ; \hat{\gamma}, \hat{c}\right)=$ $\left[1+\exp \left\{-\hat{\gamma}\left(\text { or }_{t-j}-\hat{c}\right)\right\}\right]^{-1}$. Similarly, the stock return response depends on the value taken by $s_{t}=o r_{t-j}$, and is calculated using the formula for the long-run impact of oil return:

\footnotetext{
${ }^{23}$ Plots for Bahrain, Oman, and Qatar are not displayed because long-run coefficients are not significant for positive oil price deviations.
} 
$\left[\sum_{j=0}^{N} \beta_{j}+\sum_{j=0}^{N} \phi_{j} G\left(o r_{t-j} ; \hat{\gamma}, \hat{c}\right)\right] /\left[1-\sum_{j=1}^{N} \lambda_{j}\right]$. As shown in Figure 4, the transition between both extreme regimes, $G\left(s_{t} ; \gamma . c\right)=0$ and $G\left(s_{t} ; \gamma . c\right)=1$, is smooth for Kuwait. Also, after observing Figure 4, we note that the reaction of the stock market is higher in negative oil return cases in Kuwait.

Figure 4. Logistic Functions and Long-Run Effects of Oil Prices

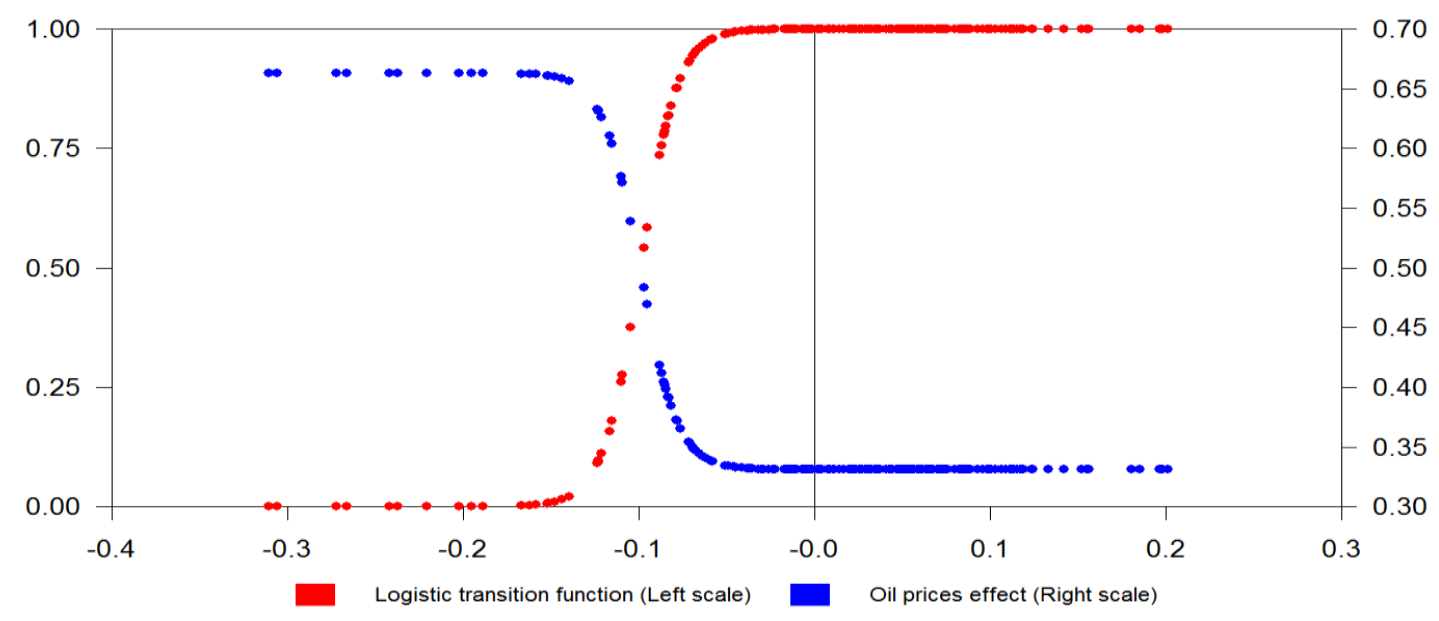

\section{Kuwait}

Note: The estimated logistic functions and long-run oil return impacts on stock markets are plotted on the y-axis. The $\mathrm{x}$-axis features/includes the different values taken by the transition variable, $s_{t}=o r_{t-j}$. The estimated logistic function is calculated using $G\left(o r_{t-j} ; \hat{\gamma}, \hat{c}\right)=\left[1+\exp \left\{-\hat{\gamma}\left(o r_{t-j}-\hat{c}\right)\right\}\right]^{-1}$. The long-run oil impact on stock return is obtained from the following formula: $\left[\sum_{j=0}^{N} \beta_{j}+\sum_{j=0}^{N} \phi_{j} G\left(o r_{t-j} ; \hat{\gamma}, \hat{c}\right)\right] /\left[1-\sum_{j=1}^{N} \lambda_{j}\right]$.

To gain further insight into the responses of GCC stock returns to oil price decreases and increases, we provide the plots of long-run oil effect estimates over time in Figure 5, with the estimated threshold levels superimposed. In Figure 5, the long-run oil effect is a time-varying coefficient that depends on the evolution of oil returns, $s_{t}=o r_{t-j}$, over time: $\left[\sum_{j=0}^{N} \beta_{j}+\sum_{j=0}^{N} \phi_{j} G\left(\right.\right.$ or $\left.\left._{t-j} ; \hat{\gamma}, \hat{c}\right)\right] /\left[1-\sum_{j=1}^{N} \lambda_{j}\right]$. The displayed plots reveal that each time the oil return falls below a given threshold, the stock return's reaction is more pronounced in Kuwait.

Indeed, when using the LSTR specification, the estimated threshold should be very close to zero $(c \simeq 0)$ in order to determine whether an oil price change is positive or negative. However, in most of cases, our LSTR models provide estimated thresholds that are, to some degree, different from the expected threshold level of $c \simeq 0$, ranging from $c=-0.10$ in Kuwait to $c \simeq 0.10$ in Oman. This might explain why we do not find significant asymmetric effects for positive and negative oil price changes on stock returns for most of our GCC countries.

Overall, when considering the presence of asymmetry with respect to oil price direction, there is a great deal of diversity among GCC countries' stock market responses. To some extent, only Kuwait corroborates the conventional wisdom that negative oil price changes have greater 
impacts on stock returns than positive oil price changes do. The strong link between Kuwait's equity market and the global factors, as asserted in our descriptive analysis, would make equities sensitive across different regimes. For Oman and Qatar, stock returns are only significant for negative or small positive deviations, but for Bahrain and Saudi Arabia, stock market reactions are not significant for either regime. In the next step, we investigate whether the ESTR specification could be more effective at capturing the presence of asymmetry and regime-switching behavior with respect to the size of oil price changes in the GCC region.

\section{Figure 5. Time-Varying Impacts of Oil Prices on Stock Returns Using LSTR Specifications}

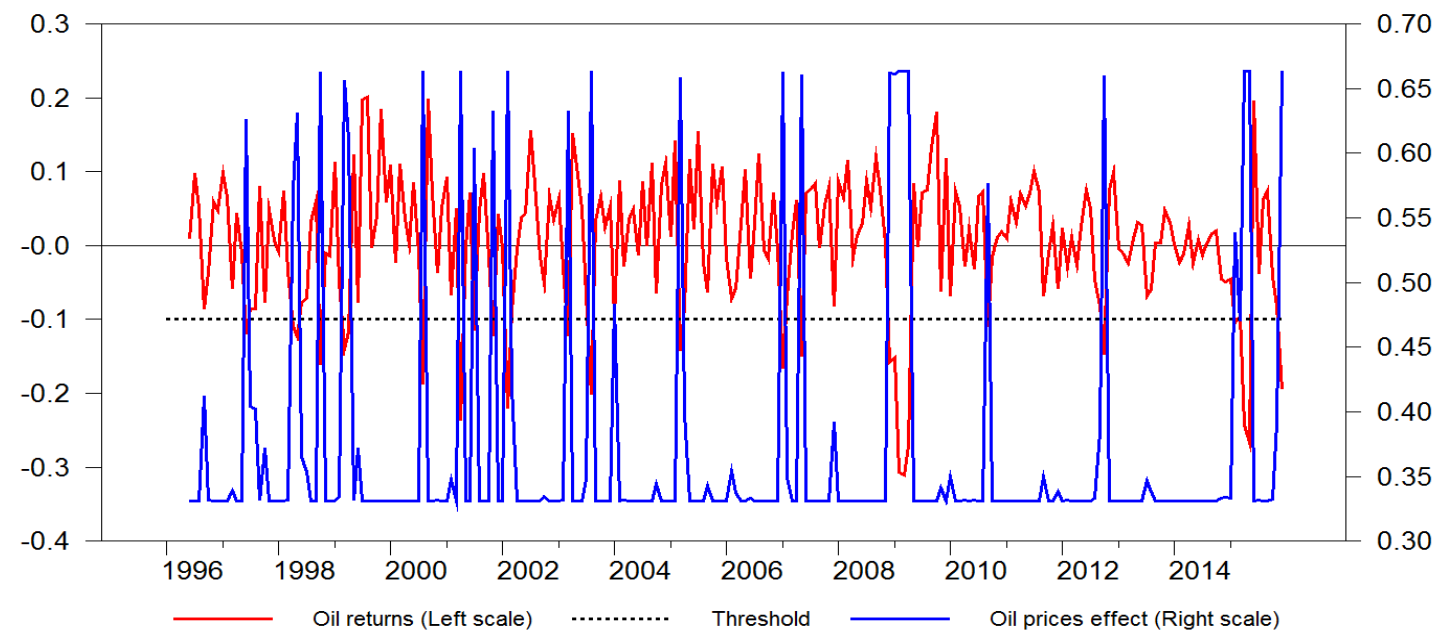

\section{Kuwait}

Note: The y-axis shows time-varying long-run oil price effects (right scale), oil returns (left scale), and threshold levels (right scale). X-axis: the monthly time index from 2004-2015. Time-varying long-run oil impacts on GCC stock returns are obtained using the following formula: $\left[\sum_{j=0}^{N} \beta_{j}+\sum_{j=0}^{N} \phi_{j} G\left(\right.\right.$ or $\left.\left._{t-j} ; \hat{\gamma}, \hat{c}\right)\right] /\left[1-\sum_{j=1}^{N} \lambda_{j}\right]$, with $G\left(\right.$ or $\left._{t-j} ; \hat{\gamma}, \hat{c}\right)=\left[1+\exp \left\{-\hat{\gamma}\left(\text { or }_{t-j}-\hat{c}\right)\right\}\right]^{-1}$.

\section{B. Asymmetry Between Small and Large Oil Price Changes}

Now, we test whether the effects that large oil price shocks exert on stock prices could be different from the effects caused by smaller shocks. In this case, the ESTR specification is more suitable for capturing asymmetric behavior with respect to the magnitude of oil price movement. Stock prices are expected to respond asymmetrically to changes in oil prices; large oil prices are associated with higher stock price responses, while small oil price changes would impact fewer stock returns.

As previously discussed, in the ESTR specification, the dynamic would be different depending on whether oil change as a transition variable $\left(s_{t}=o r_{t-j}\right)$ is close to or far away from a certain threshold. The NLS estimates of our ESTR equations are reported in Table 7. The results related to the possible asymmetric effects of small and large oil price changes on stock returns in GCC countries can be summarized as follows: First, the estimated threshold values of oil returns do not differ considerably across our sample in absolute value, ranging from 2 percent in Oman to 5.2 percent in Bahrain, with exception of Kuwait, which shows a 
threshold level close to zero $(|c|=0.003)$. The threshold levels turn out to be significant for only three GCC countries (Bahrain, Oman, and Qatar), but not for Kuwait or Saudi Arabia.

With respect to the long-term effects of oil price changes, our estimations reveal positive correlations between stock return responses and the magnitudes of oil price changes in Oman and Qatar. More specifically, as reported in Table 7, following a 1 percent oil price change, the long-run impact on Oman's stock market is equal to 0.21 percent when oil change in absolute value, $\left|o r_{t-6}\right|$, is small and close to 2 percent (the threshold being $c=0.02$ ). For a higher oil price change, $\left|o r_{t-6}\right|>2 \%$, Oman's stock return reaction is 0.63 percent. For Qatar, the long-run impact of Brent oil prices is insignificant when changes are small and close to 4.5 percent (threshold of $c \simeq 0.045$ ). This is not surprising, since stock returns could be insensitive to small oil price deviations. ${ }^{24}$ However, with considerable price variations (far from the threshold level of 4.5 percent), oil price changes exert larger, significant long-run effects on Qatar's stock returns at 0.89 percent.

Table 7. Estimated Impacts of Oil Returns on GCC Stock Markets Using ESTR Specifications

\begin{tabular}{|c|c|c|c|c|c|}
\hline & Bahrain & Kuwait & Oman & Qatar & Saudi Arabia \\
\hline Transition variable $\left(s_{t}\right)$ & $o r_{t-4}$ & $o r_{t-4}$ & $o r_{t-6}$ & $o r_{t-5}$ & $o r_{t-6}$ \\
\hline \multirow[t]{2}{*}{ Threshold $(c)$} & $0.052 *$ & -0.003 & $0.020^{*}$ & $-0.045^{* * *}$ & -0.032 \\
\hline & $(0.032)$ & $(0.012)$ & $(0.013)$ & $(0.010)$ & $(0.025)$ \\
\hline \multirow[t]{2}{*}{ Speed of transition $(\gamma)$} & 0.185 & 0.318 & 1.347 & $1.181 *$ & 1.545 \\
\hline & $(0.242$ & $(0.317)$ & $(1.221)$ & $(0.686)$ & $(2.043)$ \\
\hline \multicolumn{6}{|c|}{ Small oil changes: $G\left(s_{t} ; \gamma \cdot c\right)=0$} \\
\hline Long-run effect & $\begin{array}{c}0.459 * * \\
(0.238 \\
\end{array}$ & $\begin{array}{l}-0.011 \\
(0.101) \\
\end{array}$ & $\begin{array}{l}0.210^{*} \\
(0.140) \\
\end{array}$ & $\begin{array}{c}0.605 \\
(0.434) \\
\end{array}$ & $\begin{array}{c}0.320 \\
(0.379) \\
\end{array}$ \\
\hline \multicolumn{6}{|c|}{ Large oil changes: $G\left(s_{t} ; \gamma \cdot c\right)=1$} \\
\hline Long-run effect & $\begin{array}{c}0.810 \\
(0.757) \\
\end{array}$ & $\begin{array}{c}0.542 * * \\
(0.278) \\
\end{array}$ & $\begin{array}{c}0.633 * * * \\
(0.278) \\
\end{array}$ & $\begin{array}{c}0.890^{* *} \\
(0.446) \\
\end{array}$ & $\begin{array}{l}0.867 * \\
(0.519) \\
\end{array}$ \\
\hline$R^{2}$ & 0.433 & 0.403 & 0.307 & 0.310 & 0.414 \\
\hline$S S R_{\text {ratio }}$ & 0.745 & 0.722 & 0.803 & 0.952 & 0.774 \\
\hline$p L M_{A R(6)}$ & 0.996 & 0.962 & 0.760 & 0.791 & 0.896 \\
\hline$p L M_{A R C H(6)}$ & 0.449 & 0.810 & 0.854 & 0.043 & 0.000 \\
\hline$p L M_{C}$ & 0.141 & 0.439 & 0.376 & 0.754 & 0.218 \\
\hline$p L M_{R N C}$ & 0.368 & 0.317 & 0.266 & 0.262 & 0.444 \\
\hline
\end{tabular}

Note: Table reports the impacts of oil price changes on GCC stock returns over 2004-2015. Results are obtained from the STR equation (4) using the ESTR. Numbers in parentheses are the standards errors. *, **, and $* * *$ denote significance at the $10 \%, 5 \%$, and $1 \%$ levels, respectively. $R^{2}$ denotes the coefficient of determination. $S S R_{\text {ratio }}$ is the ratio of the sum of squared residuals between the LSTR model and the linear specification. The following rows correspond to the misspecification tests: $p L M_{A R(6)}$ is the $p$-value of the LM test of no error autocorrelation up to the sixth order. $p L M_{A R C H(6)}$ is the $p$-value of the LM test of no ARCH effects up to the sixth order. $p L M_{C}$ is the $p$-value of the LM test of parameter constancy, and $p L M_{R N C}$ is the $p$ value of the LM test of no remaining nonlinearity.

${ }^{24}$ Fiscal policy would play plays a key role in explaining the dynamic between oil price and the nonoil sector, as well as the performances of companies listed in the stock exchange. Therefore, small changes in oil prices do not seem to impact stock returns because the government can cushion the oil shock via countercyclical adjustments, given the availability of fiscal space. 
In Bahrain, however, the stock prices' long-run responses to substantial oil price changes turn out to be statistically insignificant. This counterintuitive result may be explained by the fact that we are working at an aggregate level, where composition effects may arise. Furthermore, it is worth stressing that the responses of stock returns are significantly higher for Kuwait and Saudi Arabia within the regime of large oil price variation.
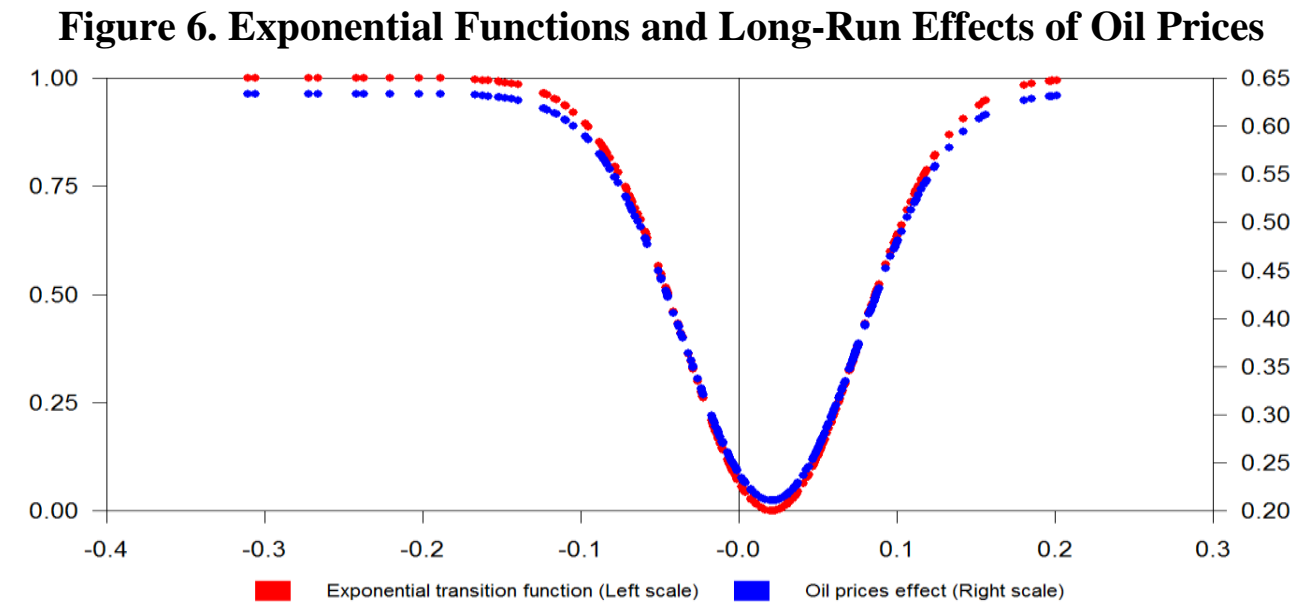

Oman

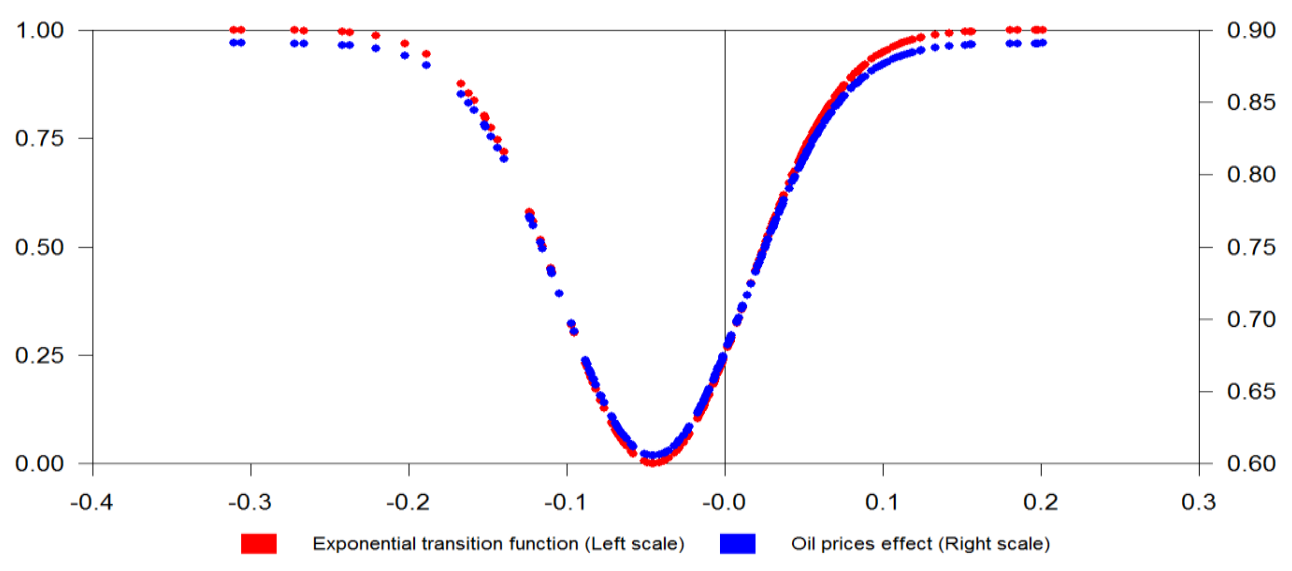

Qatar

Note: The impacts of the estimated exponential functions and long-run oil returns on the stock markets are plotted on the $y$-axis. The x-axis includes the different values taken by the transition variable, $s_{t}=o r_{t-j}$. The estimated exponential function is calculated using $G\left(o r_{t-j} ; \hat{\gamma}, \hat{c}\right)=1-\exp \left\{-\hat{\gamma}\left(o r_{t-j}-\hat{c}\right)^{2}\right\}$. The long-run oil impacts on stock returns are obtained from the following formula: $\left[\sum_{j=0}^{N} \beta_{j}+\sum_{j=0}^{N} \phi_{j} G\left(\right.\right.$ or $\left.\left._{t-j} ; \hat{\gamma}, \hat{c}\right)\right] /\left[1-\sum_{j=1}^{N} \lambda_{j}\right]$.

Figure 6 provides additional evidence for the presence of asymmetry arising from the degree of oil price variation. ${ }^{25}$ High oil price changes in absolute values elicit greater reactions from

${ }^{25}$ Plots for Bahrain are not displayed because the long-run coefficients are not significant for large oil price changes. 
equity prices than small oil price variations do. Finally, to gain more insight into the relationship between stock return and the magnitude of oil price change, we plot the timevarying coefficients over the period 2004-2015 in Figure 7. Since our study covers the episode of dramatic oil price increases throughout 2007 and early 2008, it is evident that stock return sensitivity was significantly higher than it was during periods of small price changes.

All in all, our results from the estimated ESTR models would confirm the important heterogeneity in stock return sensitivities across GCC countries. The relationship between oil price and the stock market can be considered asymmetrical, as well as regime switching, with respect to the magnitude of oil price changes in Oman and Qatar. This implies that, in these two countries, large oil price changes exert a greater impact on stock returns than small oil price variations do. Bahrain's stock market is surprisingly insensitive to large oil price changes. In Kuwait and Saudi Arabia, stock market reactions are only significant for large oil price deviations, although the estimated threshold values are not significant.

Figure 7. Time-Varying Impacts of Oil Prices on Stock Returns Using ESTR Specifications

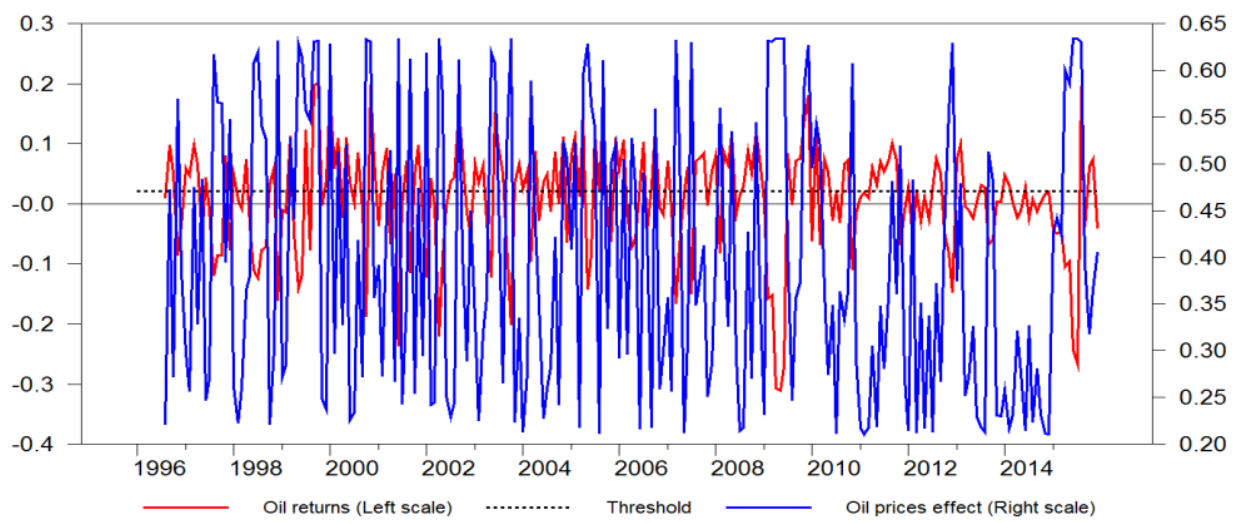

Oman

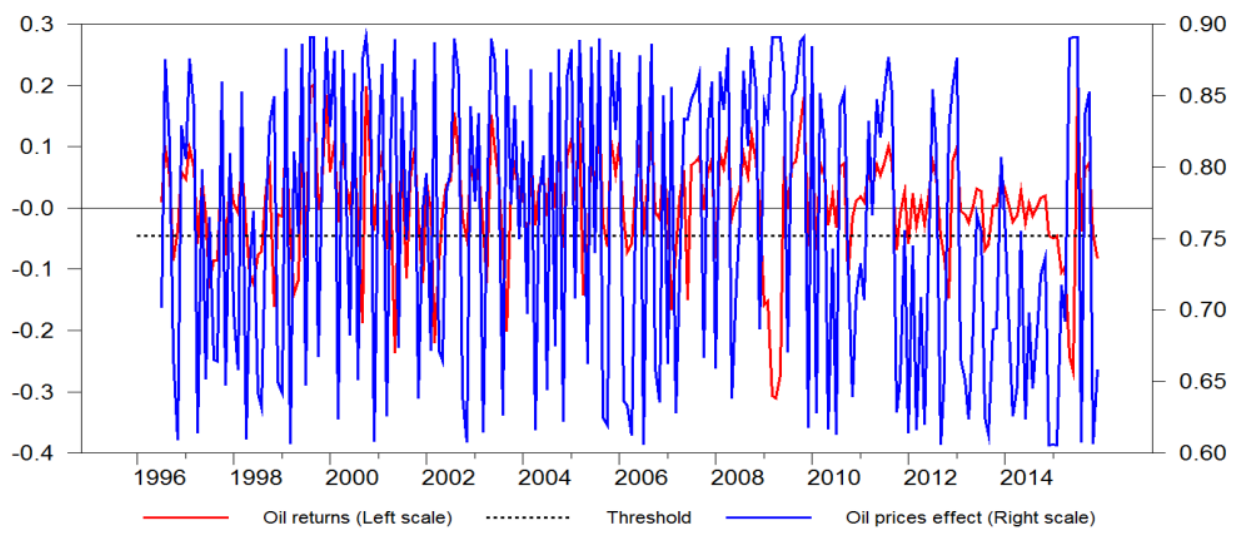

Qatar

Note: Time-varying long-run oil price effects (right scale), oil returns (left scale), and threshold levels (right scale) are plotted on the y-axis. The x-axis includes/features the monthly time index from 2004-2015. Time-varying long-run oil impacts on GCC stock returns are obtained using the following formula: $\left[\sum_{j=0}^{N} \beta_{j}+\sum_{j=0}^{N} \phi_{j} G\left(o r_{t-j} ; \hat{\gamma}, \hat{c}\right)\right] /\left[1-\sum_{j=1}^{N} \lambda_{j}\right]$, with $G\left(o r_{t-j} ; \hat{\gamma}, \hat{c}\right)=1-\exp \left\{-\hat{\gamma}\left(o r_{t-j}-\hat{c}\right)^{2}\right\}$. 


\section{Policy Discussion}

Previous studies have shown the existence of generally robust relationships between oil prices and stock markets in GCC countries. These findings are expected, given that economic activity and growth in these countries are strongly influenced by their oil export earnings. Although GCC countries have several patterns in common, they still differ to some degree in their levels of dependency on oil and in their efforts in economic reforms. Our study supports the presence of heterogeneous profiles in the reaction of GCC stock markets to oil price changes, in the sense that this sensitivity is asymmetric for some countries, but not for others. This result has important implications for both investors and policymakers.

From an investment strategy perspective, our results underscore the importance for market participants to consider differences in the sensitivities of stock returns to oil prices across GCC countries when deciding on the compositions of international stock portfolios. As highlighted in other studies, there can be substantial potential benefits to including stocks from GCC countries in portfolios that also include stocks from net oil importing countries, given that the latter group generally exhibits negative sensitivities to oil price changes. Our research emphasizes the importance of accounting for differences in stock return sensitivities across GCC countries, including potential asymmetric behaviors, when making portfolio diversification decisions and developing oil-price-related hedging strategies. Although GCC markets are still promising areas for international portfolio diversification, global investors should consider significant heterogeneous reactions in their respective financial assets.

From an economic policy perspective, our results point to the need for measures that temper and smooth the impacts of oil price changes on stock returns over time. Such measures are especially beneficial from a macroeconomic stabilization viewpoint, given that a rise/fall in equity price increases/reduces the corporate sector's wealth, thereby reinforcing the adverse impact on aggregate demand.

In GCC countries' equity markets, most stocks are held in domestic nonoil companies. ${ }^{26}$ Therefore, from a policymaker's viewpoint, stabilizing the impact of oil price change on nonoil growth is key. The main channel for such stabilization has been fiscal policy, given the GCC group's adherence to the exchange rate peg, particularly through public expenditure policy, and in view of the fledgling taxation system. Ongoing and expected structural reforms are important because they serve to diversify the economic base and increase nonoil sources of financing, thereby reducing the expected sensitivity of nonoil growth to oil-related influences over time. To illustrate, in the case of an oil price decline (the opposite channels operate for an oil price increase), oil revenue falls, leading to weaker fiscal and external positions. Equity returns fall to the extent that market participants expect an adverse impact

\footnotetext{
${ }^{26}$ Saudi Arabia's equity market is notable in the GCC, in that it also has significant direct exposure to the oil sector through stocks in the domestic petrochemical sector. Nevertheless, over three-quarters of Saudi market shares are in nonoil companies.
} 
on nonoil growth, of which the expected fiscal adjustment (especially government spending) is a key determinant. The sensitivity of stock return to price decline is likely to improve while oil price declines, insofar as market participants expect a higher probability of an adverse impact on nonoil growth due to fiscal adjustment. That impact is tempered, in that the fiscal adjustment is complemented by reforms that diversify the economic base and increase nonoil growth resilience over time.

Given the above linkages, the sensitivity of equity return to oil price depends on economic conditions and policy-related considerations that can be grouped into three broad categories.

The first category involves the market expectations relating to the impacts of oil price changes on a country's fiscal balances under current policy trends, and the magnitude of the fiscal adjustment that needs to be undertaken to achieve economically sound, or "desirable," fiscal balances that are in line with the country's fiscal sustainability and intergenerational equity objectives. The fiscal gaps between the projected fiscal balances and desirable balances have been estimated by the IMF $(2015,2016,2017)^{27}$ in the aftermath of the 201415 oil price drop. These gaps are a function of the expected path of oil prices, and the degree of the country's dependence on oil, as well as the paths of expenditure and revenuegenerating measures under current trends. Assuming that lower oil prices are expected to persist over the longer term, we estimate these fiscal gaps to be in the range of 10 to 25 percentage points of nonoil GDP for Bahrain, Kuwait, Oman, and Saudi Arabia, and 5 percent for Qatar and the UAE.

The second key category is the pace at which fiscal adjustment measures are implemented to raise fiscal balances toward their desired levels and eliminate fiscal gaps. Fiscal adjustment that is smoothed over time, ceteris paribus, tends to limit the adverse impact on nonoil growth, corporate profits, and equity markets. That pace, in turn, is determined by the fiscal space available, as measured by the size of a government's financial assets (fiscal buffers), and its capacity to borrow. A higher fiscal space enables a smoother fiscal adjustment, thereby reducing the impact of oil price change on the equity market. In addition, the greater space, by enabling easier access to international bond markets, tempers the impact of oil price change on domestic financing requirements and liquidity, further limiting the impacts on equity prices. The IMF's (2015) assessment - measured in terms of financial assets - is that Kuwait, Qatar, and the UAE have relatively comfortable buffers; current trends show that their assets are sufficient to finance their fiscal deficits for 20 more years. On the other hand, Bahrain's, Oman's, and Saudi Arabia's financial assets are sufficient to finance their deficits for less than five years, according to current trends. As measured by their borrowing capacities, the assessments of the debt-to-GDP projected paths for 2015 to 2020 suggests that Kuwait, Saudi Arabia, and the UAE have the widest fiscal spaces, and Oman and Qatar have intermediate positions, while Bahrain is in a relatively vulnerable position.

\footnotetext{
${ }^{27}$ See the issues of the IMF's Regional Economic Outlook relating to the Middle East and Central Asia for the years 2015 to 2017 .
} 
The third key category relates to the degree of diversity within the GCC economy, as reflected in the share of oil fiscal revenue in total revenues (about 70 percent for the UAE, and between 84 and 91 percent for the other GCC countries, using the average for 20112014). The GCC economy's diversification hinges on the prospect of reducing that share over time through structural reform.

In terms of structural reform signals, all six GCC countries have set out broadly similar reform plans in the aftermath of the 2014 oil price decline. They have also made progress in setting out and clearly communicating credible, well-defined medium-term fiscal frameworks. Within each framework, an important objective has been the implementation of adjustment policies that are supported by structural reforms to diversify their economies away from the hydrocarbon sector, and expand the contribution of the private sector. In that regard, the UAE has made a head start in diversifying its export base, including in the areas of tourism, business, and transport services. Bahrain has also made important strides in expanding financial services and food processing. Saudi Arabia, in line with its strategic development plan (Vision 2030), has initiated significant reforms in the equity and bond markets to encourage greater foreign investment, and has also made progress in privatization. However, GCC countries have been uniformly slow in expanding their nonoil revenue bases, delaying the implementation of regional VAT frameworks. ${ }^{28}$

Key determinants of asymmetry in stock price reaction include the interplay between the three aforementioned factors, and the impact on nonoil growth. However, it is difficult to predict a priori the weight that market participants for a particular country would give each of the three factors in forming expectations regarding the impact of a given oil price change. In particular, the econometric results of our paper indicate that asymmetrical stock price reactions occur in Kuwait, Oman, and Qatar, but not in the other GCC countries.

What is special about these three countries with respect to the considerations set out above? In Kuwait's and Oman's cases, the fiscal gaps are relatively high, estimated at 10 and 25 percent of nonoil GDP (respectively). However, for Qatar, the fiscal gap is among the lowest in the GCC group, at 5 percent of nonoil GDP. In terms of fiscal space, Oman's financial assets are insufficient to finance its deficits for more than five years, and it has an intermediate position in terms of the path of the public debt-to-GDP ratio. Both Kuwait and Qatar fare relatively well in terms of their fiscal spaces, with ample financial assets and relatively good positions regarding their public debt-to-GDP ratios. All three countries' economies are inadequately diversified, with ratios of hydrocarbon fiscal revenue to total revenue being well above 80 percent.

\footnotetext{
${ }^{28}$ Saudi Arabia and the UAE began implementing VATs in January 2018.
} 
In sum, Kuwait, Oman, and Qatar each have at least one feature that, as a result of a negative or large oil price change, could potentially signal a high likelihood of substantial fiscal adjustment. However, the combination of relevant factors is different in each of the three countries. While Oman faces challenges due to all three factors, in Kuwait and Qatar, the main operative factors appear to be their high degrees of reliance on hydrocarbon revenues.

\section{CONCLUSION}

This paper investigates the asymmetric mechanisms in stock markets' responses to oil price changes. The recent spectacular swings in the crude oil market, as well as the dramatic changes in the financial environment since the eruption of the subprime crisis, have revived interest in the asymmetric, nonlinear relationship between oil price and the stock market. While the bulk of the existing empirical literature has devoted more attention to the asymmetry arising from the direction of oil price change, our study proposes to implement a relevant econometric method that enables us to explore the two possible sources of asymmetry in stock price reactions: the direction and magnitude of oil price change. We use the class of nonlinear STR models, where different regimes can be identified with respect to estimated thresholds. To capture the asymmetry arising from the direction of oil price shock, we use the LSTR, which is appropriate for separating oil price into positive and negative changes. However, the ESTR is more suitable for distinguishing between large and small oil price changes when capturing asymmetric behavior with respect to the size of oil price movement. Our study includes six GCC countries (Bahrain, Kuwait, Oman, Qatar, Saudi Arabia, and the UAE), and uses monthly data from January 2004-December 2015. When investigating the presence of asymmetry with respect to the direction of oil price change, our results reveal a great deal of diversity in the individual responses of GCC stock markets. For example, only Kuwait's stock market reactions to oil price changes are not significantly equal for both rising and falling oil prices. The ESTR specification, which helps us to examine asymmetry with respect to oil price change's magnitude, confirms the presence of heterogeneous profiles in GCC equity markets. More specifically, we find that Omani and Qatari stock markets exhibit higher sensitivities to large oil price changes than to small ones.

Our empirical results document stock markets' heterogeneous reactions across GCC countries, which researchers, regulators, and market actors should consider. Being OPEC members, and therefore, part of the Organization's decision-making process, GCC countries should carefully study the impacts of oil price variations on their own economies and stock markets. The significant asymmetries in the relationships between oil prices and stock markets in some GCC nations (Kuwait, Oman, and Qatar), but not in others (Bahrain, Saudi Arabia, and the UAE), means investors should exercise more caution when deciding on the compositions of international stock portfolios.

Our findings also underline the role of economic policy in reducing the sensitivity of stock return to oil price change. From a policy perspective, our framework could serve to identify countries in which asymmetries prevail, where policy action would be especially beneficial from the economic stabilization and reform perspectives. These include policies that ensure consistency with fiscal sustainability and intergenerational equity goals, as well as structural reforms that diversify economic and revenue bases. 
Further research is required to extend our analysis. First, the asymmetric mechanisms in stock markets' responses to oil price variations in GCC countries are likely to be different across various economic sectors. Therefore, a sectoral analysis of this link could provide additional and disaggregated results and complement our analysis. Second, since our analysis does not cover the more recent GCC diplomatic crisis (2017) due to lack of data availability, future studies should consider such episodes of geopolitical tensions. Recently, Caldara and Iacoviello (2018) have proposed a monthly index of geopolitical risk, which is constructed to measure risks associated with wars, tensions between states, and terrorist acts that affect the normal course of international relations. Third, to gain insight into the phenomenon of asymmetry, it would be beneficial to test for nonlinear causal relationships between oil and stock markets in GCC countries. One option would be to conduct a nonlinear Granger causality test based on the STR framework developed by Skalin and Teräsvirta (1999). 


\section{REFERENCES}

Akoum, I., M. Graham, J. Kivihaho, J. Nikkinen, and M. Omran, 2012, "Co-movement of oil and stock prices in the GCC region: A wavelet analysis," The Quarterly Review of Economics and Finance, Vol. 52, pp. 385-394.

Al-Maadid, A., F. Spagnolo, and N. Spagnolo, 2016. "Stock Prices and Crude Oil Shocks: The Case of GCC Countries," in Handbook of Frontier Markets.

Almohaimeed, A., and N. Harrathi, 2013, "Volatility Transmission and Conditional Correlation between Oil prices, Stock Market and Sector Indexes: Empirics for Saudi Stock Market," Journal of Applied Finance and Banking, Vol. 3, No. 4, pp. 125-141.

Arouri, M., A. Lahiani, and D. Nguyen, 2011, "Return and volatility transmission between world oil prices and stock markets of the GCC countries," Economic Modeling, Vol. 28, No. 4, pp. 1815-1825.

Arouri, M., and C. Rault, 2012, "Oil prices and stock markets in GCC countries: empirical evidence from panel analysis," International Journal of Finance and Economics, Vol.17, pp. 242-253.

Arouri, M., Rault C., and F. Teulon, 2014, "Economic policy uncertainty, oil price shocks and GCC stock markets", Economics Bulletin, Vol. 34 No. 3 pp. 1822-1834.

Baker, S. R., N. Bloom, and S. J. Davis, 2016, Measuring Economic Policy Uncertainty, The Quarterly Journal of Economics, Volume 131, Issue 4, pp. 1593-1636.

Balcilar, M., R. Gupta, and S. M. Miller, 2015, "Regime switching model of US crude oil and stock market prices: 1859 to 2013,” Energy Economics Vol. 49, pp. 317-327.

Bittlingmayer, G, 2005, “Oil and stocks: Is it war risk?": University of Kansas manuscript, December 29, 2005.

Caldara, D. and M., Iacoviello, (2018), Measuring Geopolitical Risk. FRB International Finance Discussion Paper No. 1222.

Cologni A, and M. Manera, 2008, "Oil prices, inflation and interest rates in a structural cointegrated VAR model for the G-7 countries," Energy Economics, Vol. 30, No. 3, pp. 856888.

Dutta A., J. Nikkinen, and T. Rothovius, 2017, "Impact of oil price uncertainty on Middle East and African stock markets," Energy 123, pp. 189-197.

Elliott, G., T. Rothenberg, and J. Stock, 1996, "Efficient Tests for an Autoregressive Unit Root,” Econometrica, Vol. 64, No. 4, pp. 813-836.

Eitrheim. Ø., and T. Teräsvirta, 1996, "Testing the adequacy of smooth transition autoregressive models," Journal of Econometrics, Vol. 74, pp. 59-76. 
Granger, C. W., and G. Yoon, 2002, "Hidden Cointegration," Department of Economics Discussion Paper 2002-02, University of California, San Diego.

Gregory, A., and H. Hansen, 1996, "Residual-based tests for cointegration in models with regime shifts," Journal of Econometrics, Vol. 70, No 4, pp. 99-126.

Gronwald M., 2008, ““'Large Oil Shocks and the US Economy: Infrequent Incidents with Large Effects," Energy Journal, Vol. 29, No. 1, pp.151-171.

Hamilton, J. D., 1996, "This is what happened to the oil price-macroeconomy relationship," Journal of Monetary Economics, Vol. 38, No.2, pp. 215-220.

Jouini, J., and N. Harrathi, 2014, "Revisiting the shock and volatility transmissions among GCC, stock and oil markets: a further investigation," Economic Modelling, Vol. 38, pp. 486494.

Kilian L, 2008, "Exogenous Oil Supply Shocks: How Big Are They and How Much Do They Matter for the U.S. Economy?" Review of Economics and Statistics, Vol. 90, No. 2, pp. 216240.

Koop, G. and S.M. Potter (2000), Nonlinearity, structural breaks or outliers in economic time series? in W. A. Barnett, D. F. Hendry, S. Hylleberg, T. Teräsvirta, D. Tjøstheim and A. H. Würtz (eds.), Nonlinear Econometric Modeling in Time Series Analysis, Cambridge: Cambridge University Press.

Lumsdaine, R. L., and D. H. Papell, 1997, "Multiple Trend Breaks and the Unit-Root Hypothesis," Review of Economics and Statistics, Vol. 79, No. 2, pp. 212-218.

Mohanty, S. K., M. Nandha, A. Q. Turkistani, and M. Y. Alaitani, 2011, "Oil price movements and stock market returns: Evidence from Gulf Cooperation Council (GCC) countries," Global Finance Journal, Vol. 22, No.1, pp. 42-55.

Mork, K., 1989, "Oil and the Macroeconomy When Prices Go Up and Down: An Extension of Hamilton's Results," Journal of Political Economy, Vol. 97, No. 3, pp. 740-744.

Park, J., and R. A. Ratti, 2008, "Oil price shocks and stock markets in the U.S. and 13 European countries,” Energy Economics, Vol. 30, No. 5, pp. 2587-2608.

Reboredo J. C., and A., Ugolini, 2016, "Quantile dependence of oil price movements and stock returns," Energy Economics Vol. 54, No 1, pp. 33-49.

Sadorsky, P., 1999, "Oil price shocks and stock market activity," Energy Economics Vol 21, No 5, pp. 449-469.

Sim, N., and H. Zho, 2015, "Oil prices, US stock return, and the dependence between their quantiles," Journal of Banking and Finance, Vol. 55, pp. 1-8. 
Skalin, J. and T. Teräsvirta, 1999, "Another Look at Swedish Business Cycles, 1861-1988", Journal of Applied Econometrics, Vol. 14, no 4, pp 359-78.

Teräsvirta. T., 1994, "Specification, Estimation, and Evaluation of Smooth Transition Autoregressive Models, Journal of the American Statistical Association, Vol. 29, No. 425, pp. 208-218.

Teräsvirta, T., 1998, "Modelling economic relationships with smooth transition regressions," in Handbook of Applied Economic Statistics, ed. by A. Ullah and D. E. A. Giles, (New York: Marcel Dekker).

van Dijk, D., P. Franses, and Lucas (1999), "Testing for smooth transition nonlinearity in the presence of additive outliers", Journal of Business and Economic Statistics, Vol. 17, No. 2, pp. 217-235.

van Dijk, D., T. Teräsvirta, and P. Franses, 2002, "Smooth Transition Autoregressive Models: A Survey of Recent Developments," Econometric Reviews, Vol. 21, No 1, pp. 1-47.

Zivot. E., and K. Andrews, 1992, "Further Evidence on the Great Crash, the Oil-Price Shock, and the Unit-Root Hypothesis," Journal of Business and Economic Statistics, Vol. 10, No 3, pp. 251-70. 


\section{APPENDIX. FULL RESULTS FROM LSTR AND ESTR MODELS}

\section{Table A1. Full Estimation Results from LSTR Specifications}

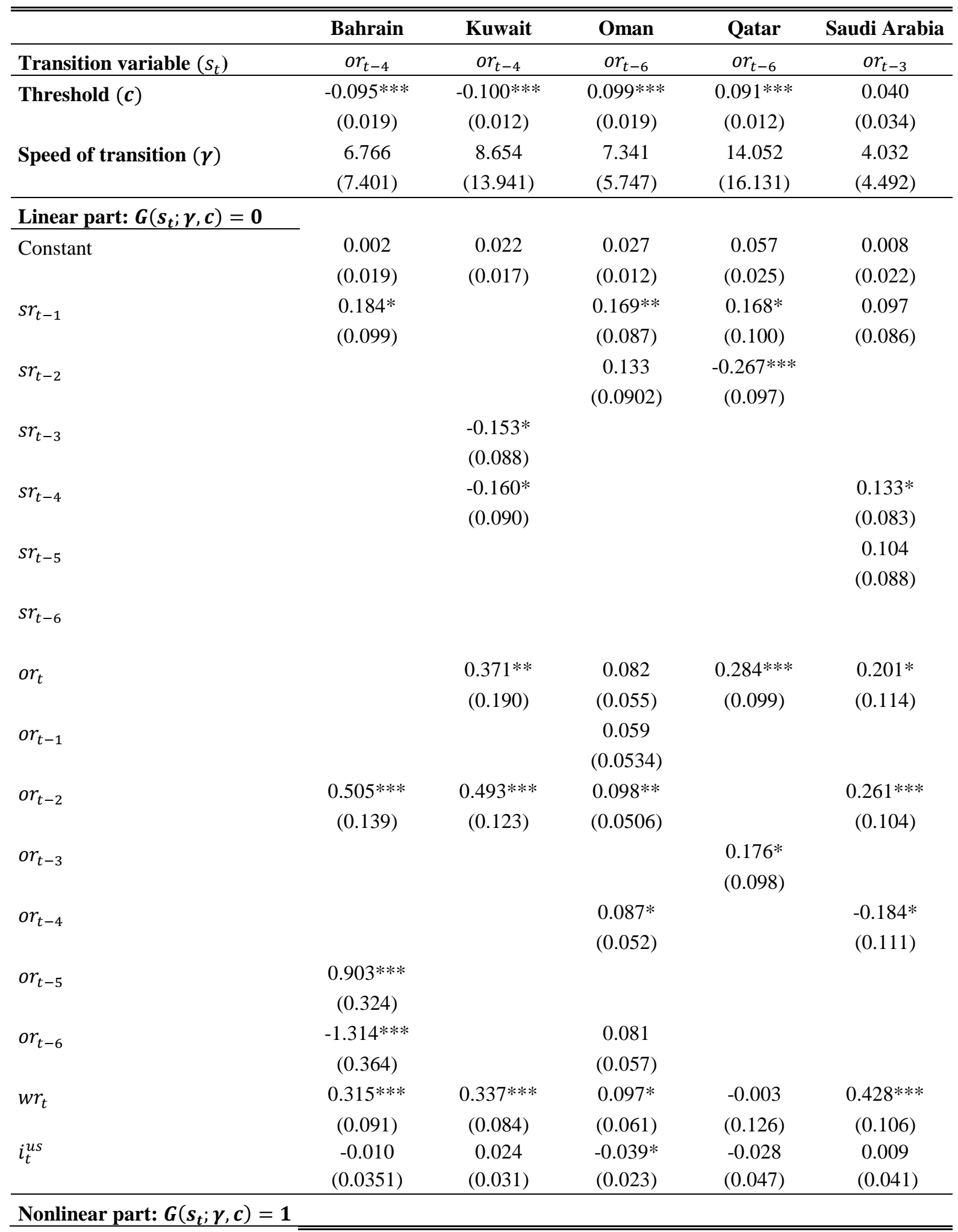




\begin{tabular}{|c|c|c|c|c|c|}
\hline$o r_{t}$ & & & $\begin{array}{c}0.718^{* *} \\
(0.391)\end{array}$ & $\begin{array}{l}0.566^{*} \\
(0.344)\end{array}$ & $\begin{array}{c}-0.499 * * \\
(0.240)\end{array}$ \\
\hline$o r_{t-1}$ & & & & $\begin{array}{l}0.493 * \\
(0.285)\end{array}$ & $\begin{array}{c}0.603 * * \\
(0.276)\end{array}$ \\
\hline$o r_{t-2}$ & $\begin{array}{c}-0.471 * * * \\
(0.171)\end{array}$ & $\begin{array}{c}-0.435 * * * \\
(0.147)\end{array}$ & & & $\begin{array}{l}-0.264 \\
(0.220)\end{array}$ \\
\hline$o r_{t-3}$ & & & & $\begin{array}{l}-0.493 \\
(0.323)\end{array}$ & \\
\hline$o r_{t-4}$ & & & & & \\
\hline$o r_{t-5}$ & $\begin{array}{c}-0.893 * * * \\
(0.339)\end{array}$ & & $\begin{array}{c}-1.035^{* * *} \\
(0.385)\end{array}$ & $\begin{array}{c}-1.201 * * * \\
(0.480)\end{array}$ & \\
\hline$o r_{t-6}$ & $\begin{array}{c}1.181 * * * \\
(0.368)\end{array}$ & & & $\begin{array}{c}0.415 \\
(0.266)\end{array}$ & \\
\hline
\end{tabular}

Note: Table reports estimates of STR equation (4) using the LSTR over 2004-2015. Numbers in parentheses are the standard errors. *,** and, $* * *$ denote significance at the $10 \%, 5 \%$, and $1 \%$ levels, respectively. 
Table A2. Full Estimation Results from ESTR Specifications

\begin{tabular}{|c|c|c|c|c|c|}
\hline & Bahrain & Kuwait & Oman & Qatar & Saudi Arabia \\
\hline Transition variable $\left(s_{t}\right)$ & $o r_{t-4}$ & $o r_{t-4}$ & $o r_{t-6}$ & $o r_{t-5}$ & $o r_{t-6}$ \\
\hline Threshold (c) & $\begin{array}{l}0.052 * \\
(0.032)\end{array}$ & $\begin{array}{l}-0.003 \\
(0.012)\end{array}$ & $\begin{array}{l}0.020^{*} \\
(0.013)\end{array}$ & $\begin{array}{c}-0.045^{* * *} \\
(0.010)\end{array}$ & $\begin{array}{l}-0.032 \\
(0.025)\end{array}$ \\
\hline Speed of transition $(\gamma)$ & $\begin{array}{c}0.185 \\
(0.242) \\
\end{array}$ & $\begin{array}{c}0.318 \\
(0.317) \\
\end{array}$ & $\begin{array}{c}1.347 \\
(1.221) \\
\end{array}$ & $\begin{array}{l}1.181 * \\
(0.686) \\
\end{array}$ & $\begin{array}{c}1.545 \\
(2.043) \\
\end{array}$ \\
\hline \multicolumn{6}{|c|}{ Linear part: $G\left(s_{t} ; \gamma, c\right)=0$} \\
\hline Constant & $\begin{array}{l}-0.006 \\
(0.019)\end{array}$ & $\begin{array}{l}0.0168 \\
(0.017)\end{array}$ & $\begin{array}{c}0.029 \\
(0.015)\end{array}$ & $\begin{array}{c}0.072 \\
(0.026)\end{array}$ & $\begin{array}{l}-0.003 \\
(0.022)\end{array}$ \\
\hline$s r_{t-1}$ & $\begin{array}{c}0.153 \\
(0.100)\end{array}$ & & $\begin{array}{c}0.138 \\
(0.101)\end{array}$ & $\begin{array}{c}0.286 * * * \\
(0.097)\end{array}$ & \\
\hline$s r_{t-2}$ & & & $\begin{array}{c}0.137 \\
(0.098)\end{array}$ & $\begin{array}{l}-0.106 \\
(0.093\end{array}$ & \\
\hline$s r_{t-3}$ & & $\begin{array}{c}-0.146^{*} \\
(0.092)\end{array}$ & & $\begin{array}{c}0.127 \\
(0.095)\end{array}$ & \\
\hline$s r_{t-4}$ & & $\begin{array}{c}-0.189 * * \\
(0.092)\end{array}$ & & & $\begin{array}{c}0.131 \\
(0.087)\end{array}$ \\
\hline$s r_{t-5}$ & $\begin{array}{c}0.130 \\
(0.092)\end{array}$ & & & & $\begin{array}{c}0.104 \\
(0.094)\end{array}$ \\
\hline$s r_{t-6}$ & & & $\begin{array}{l}-0.096 \\
(0.095)\end{array}$ & & $\begin{array}{c}0.117 \\
(0.088)\end{array}$ \\
\hline$o r_{t}$ & $\begin{array}{l}0.159 * \\
(0.099\end{array}$ & $\begin{array}{l}0.148^{*} \\
(0.093)\end{array}$ & & $\begin{array}{c}0.291 * * \\
(0.141)\end{array}$ & \\
\hline$o r_{t-1}$ & & & $\begin{array}{c}0.206 * * \\
(0.107)\end{array}$ & $\begin{array}{c}0.437 * * * \\
(0.177)\end{array}$ & \\
\hline$o r_{t-2}$ & & & $\begin{array}{c}0.096 \\
(0.088)\end{array}$ & $\begin{array}{c}-0.613 * * * \\
(0.213)\end{array}$ & $\begin{array}{l}0.264^{*} \\
(0.155\end{array}$ \\
\hline$o r_{t-3}$ & & & $\begin{array}{l}-0.129 \\
(0.108)\end{array}$ & & \\
\hline$o r_{t-4}$ & $\begin{array}{c}0.169 \\
(0.142\end{array}$ & & & $\begin{array}{l}-0.318^{*} \\
(0.202)\end{array}$ & $\begin{array}{l}-0.280 * \\
(0.172)\end{array}$ \\
\hline$o r_{t-5}$ & & & & & $\begin{array}{c}0.223 \\
(0.201)\end{array}$ \\
\hline$o r_{t-6}$ & & $\begin{array}{l}-0.163^{*} \\
(0.090)\end{array}$ & & $\begin{array}{c}0.623 * * * \\
(0.194)\end{array}$ & \\
\hline$w r_{t}$ & $\begin{array}{c}0.323 * * * \\
(0.095)\end{array}$ & $\begin{array}{c}0.319 * * * \\
(0.084)\end{array}$ & $\begin{array}{c}0.058 \\
(0.068)\end{array}$ & $\begin{array}{l}-0.127 \\
(0.122)\end{array}$ & $\begin{array}{c}0.476^{* * *} \\
(0.111)\end{array}$ \\
\hline$i_{t}^{u s}$ & $\begin{array}{l}-0.016 \\
(0.036) \\
\end{array}$ & $\begin{array}{c}0.005 \\
(0.032) \\
\end{array}$ & $\begin{array}{l}-0.013 \\
(0.025) \\
\end{array}$ & $\begin{array}{c}0.038 \\
(0.043) \\
\end{array}$ & $\begin{array}{c}0.000 \\
(0.042) \\
\end{array}$ \\
\hline Nonlinear part: $G\left(s_{t} ; \gamma, c\right.$ & & & & & \\
\hline$o r_{t}$ & & & $\begin{array}{c}0.344 * * \\
(0.180)\end{array}$ & & \\
\hline
\end{tabular}




\begin{tabular}{|c|c|c|c|c|c|}
\hline$o r_{t-1}$ & & & $\begin{array}{l}-0.252 \\
(0.197)\end{array}$ & $\begin{array}{c}-0.489 * * * \\
(0.267)\end{array}$ & $\begin{array}{l}0.354^{*} \\
(0.220)\end{array}$ \\
\hline$o r_{t-2}$ & $\begin{array}{c}0.735 * * \\
(0.394)\end{array}$ & $\begin{array}{c}0.739 * * \\
(0.322)\end{array}$ & & $\begin{array}{c}0.922 \\
(0.256)\end{array}$ & \\
\hline$o r_{t-3}$ & & & $\begin{array}{l}0.255^{*} \\
(0.147)\end{array}$ & & \\
\hline$o r_{t-4}$ & & & & $\begin{array}{c}0.480 * * * \\
(0.248)\end{array}$ & \\
\hline$o r_{t-5}$ & $\begin{array}{c}0.720 \\
(0.657)\end{array}$ & & & $\begin{array}{l}-0.502 \\
(0.364)\end{array}$ & \\
\hline$o r_{t-6}$ & $\begin{array}{c}-1.204 * \\
(0.756)\end{array}$ & & & $\begin{array}{c}-0.715^{* * *} * \\
(0.247)\end{array}$ & \\
\hline
\end{tabular}

Note: Table reports estimates of STR equation (4) using ESTR over 2004-2015. Numbers in parentheses are the standard errors. *, $* *$, and $* * *$ denote significance at the $10 \%, 5 \%$, and $1 \%$ levels, respectively. 